\title{
Pricing and Logistics Service Decisions in Platform-Led Electronic Closed-Loop Supply Chain with Remanufacturing
}

\author{
Kai Liu ${ }^{1,2, *}$, Chunfa $\mathrm{Li}^{1}$ and Runde Gu ${ }^{1, *(D)}$ \\ 1 School of Management, Tianjin University of Technology, Tianjin 300384, China; chunfali@163.com \\ 2 School of Mathematical Science, Huaibei Normal University, Huaibei 235000, China \\ * Correspondence: liuk0519@163.com (K.L.); rundegu@stud.tjut.edu.cn (R.G.); Tel.: +86-151-0561-2725 (K.L.)
}

Citation: Liu, K.; Li, C.; Gu, R. Pricing and Logistics Service Decisions in Platform-Led Electronic Closed-Loop Supply Chain with Remanufacturing. Sustainability 2021, 13, 11357. https://doi.org/10.3390/ su132011357

Academic Editor: Claudia Colicchia

Received: 13 August 2021

Accepted: 11 October 2021

Published: 14 October 2021

Publisher's Note: MDPI stays neutral with regard to jurisdictional claims in published maps and institutional affiliations.

Copyright: (c) 2021 by the authors. Licensee MDPI, Basel, Switzerland. This article is an open access article distributed under the terms and conditions of the Creative Commons Attribution (CC BY) license (https:/ / creativecommons.org/licenses/by/ $4.0 /)$.

\begin{abstract}
With the continuous development of e-commerce, it has become normal for the manufacturer to sell products and to collect used products through e-commerce platforms (platform for short). We consider an electronic closed-loop supply chain (E-CLSC) where we composed a manufacturer with remanufacturing capability and a platform that can provide logistics services. The purpose of this paper is to address whether the manufacturer should directly collect used products from the consumer under the platform. Specifically, we have developed four game models, namely model $\mathrm{N}$ (no collection), model M (the manufacturer collects), model $\mathrm{E}$ (the platform collects), and model $\mathrm{T}$ (the third-party collects) and derived the optimal pricing decisions, logistics service level, and collection rate for E-CLSC members. We found that remanufacturing used products is conducive to increasing the profits of the manufacturer and the platform as well as to increasing the utility of the consumer. Under the same conditions, for the manufacturer, the platform, and the consumer, the optimal choice is that the manufacturer directly collects the used products from the consumer. If the manufacturer is unable to establish an effective collection channel, he should consider outsourcing to a contractor and should consider the platform to be under the same conditions. Numerical examples are also given to verify the proposed results.
\end{abstract}

Keywords: electronic closed-loop supply chain (E-CLSC); e-commerce platform; remanufacturing; Stackelberg game; pricing and logistics service decisions

\section{Introduction}

Due to the rapid development and widespread application of mobile Internet technology and e-commerce, the transformation and upgrade of the traditional supply chain to an electronic supply chain have become inevitable, as Taobao.com and JD.com have become actual product sale and recycling channels in China [1,2]. According to the relevant data from the Ministry of Commerce of China, the market size of e-commerce retail (online retail) in China increased from CNY 0.5 trillion in 2010 (penetration rate of about 3.6\%) to CNY 9.0 trillion in 2018 (penetration rate of 26.6\%), an increase of nearly 20 times, and the penetration rate is growing exponentially. On the other hand, with the acceleration of information technology updates and the continuous improvement of people's living standards, the life cycle of mobile phones, computers, printers, air conditioners, refrigerators, washing machines, and other electrical and electronic equipment has been shortened, and the speed of renewal has been accelerated [3-5]. For example, the timeframe of a technology product upgrade for consumer electronics manufacturers such as Apple, Huawei, and Xiaomi are within one year. After a certain period, electronic products are replaced by new models or are discontinued [6-8]. Gree, Haier, Midea and other home appliance enterprises generally do not set warranty periods to be more than 1-3 years long in order to encourage consumers to trade-in their products for services. Companies such as Intel and HP have reduced product development cycles from four to five years to four to five months. Therefore, the amount of WEEE will maintain sustainable growth in the future [9-11]. However, we find 
that WEEE remanufacturing is an effective way to save valuable resources and to support a circular economy [12-15].

In recent years, the deep integration of next-generation information and communication technology within the manufacturing industry, retail service industry, and resource recycling industry has promoted the rapid development and implementation of the E-closed-loop supply chain (E-CLSC) as the core of the e-commerce platform (referred to the platform). It has a huge impact and influence on product sales, recycling operation, and closed-loop supply chain coordination. In the E-CLSC system, many manufacturers sell products to customers through e-commerce platforms and recycle waste products for remanufacturing [16]. The emergence of an online recycling channel has brought a significant breakthrough to reverse channel management $[1,2,17,18]$. It helps to cross offline recycling channels due to limitations of space and physical distance and to reduce the search cost of recyclers and the hassle cost of consumers during the recycling process. In reality, online recycling can improve the recycling efficiency of used products [19]. Therefore, how to design a proper recycling channel under the leadership of an e-commerce platform has become a vital issue in the field of closed-loop supply chain management.

Inspired by the practices of firms, this paper aims to address the above issues, taking into account online recycling and consumer channel preferences. Although some studies have explored the structural configuration of online recycling channels [1,2,17-19], few of them consider the level of product logistics services and consumer responses to recycling activities. In order to fill this gap, we studied the recycling channel choices of enterprises when considering these two key factors. To simplify the model and to reduce conceptual confusion, we assumed that enterprises collect waste products, remanufacture them, and sell them. In particular, we considered a closed-loop supply chain composed of a manufacturer with manufacturer capability and an e-commerce platform with self-established logistics services and sought to solve the following research questions:

1. What are optimal decisions for the manufacturer and the e-commerce platform under different structures?

2. From the perspective of the manufacturer, the e-commerce platform, the consumer, and the ecological environment, which structure is more favored?

3. How do vital parameters affect the optimal decisions of the manufacturer and the e-commerce platform?

To solve these questions, we considered three different recycling channel structures for the manufacturer and the e-commerce platform. Firstly, according to the theory of consumer behavior, the product market demand is deduced, and then the optimal pricing and logistics service decisions under different scenarios are obtained. Through the comparison of equilibrium strategies and numerical examples, we gained some interesting insights that can help guide the actual operation of enterprises. Secondly, on the basis of theoretical analysis, we found that the recycling and remanufacturing of used products not only benefits the manufacturer but also the e-commerce platform and the consumer.

The rest of this paper is structured as follows: Some of the literature related to this research is reviewed in Section 2. The problem description and hypotheses are presented in Section 3. The models and results are presented in Section 4 . Section 5 contains a comparison of the results of the four models as well as a sensitivity analysis of the related parameters. Section 6 extends the basic model from the perspectives of manufacturers, e-commerce platforms, consumers, and ecological environment. Finally, the conclusions and future research are given in Section 7.

\section{Literature Review}

The first stream of relevant research to our paper mainly focuses on optimal pricing decisions in CLSCs. For example, Wang et al. [4] investigated the influence of a reward and punishment mechanism on the pricing strategy of a two-cycle closed-loop supply chain. Zhang et al. [5] studied retail service and pricing decisions in the dual-channel remanufacturing closed-loop supply chain. Atasu et al. [12] found that remanufacturing can 
consider the green preferences of consumers as an effective marketing strategy. Ferrer and Swaminathan [20] proposed a mathematical model to consider the fact that manufacturers produce new products and remanufactured products at the same time to optimize the enterprise profits under the constraints of quantity and price. The research pointed out that over time, enterprises often use remanufactured products and new products with recycled cores to achieve profit growth. Chen and Chang [21] used Lagrangean relaxation and dynamic programming schemes to explore the optimal pricing strategies for new and remanufactured products in the closed-loop supply chain. Xiong et al. [22] studied the impact of the manufacturer's remanufacturing strategies on his supplier decisions. Wu [23] examined price and service competition between new and remanufactured products in a two-level supply chain. Li et al. [24] studied the pricing and service effort strategies of a dual-channel supply chain with the showrooming effect. Duan et al. [25] studied the pricing strategies of a multi-cycle E-closed-loop supply chain by considering consumer product preferences. He et al. [26] proposed a competitive collection pricing strategy under inconvenient channels in the closed-loop supply chain.

At present, most studies on closed-loop supply chain optimization modeling assume that the manufacturer is dominant. However, with the rapid development of the retail industry in recent years, strong retailers such as Wal-Mart, Gome, and Suning have emerged, and the corresponding dominant position of different supply chain channel members has also changed significantly. Tsay et al. [27] have pointed out that the transfer of channel power from manufacturers to retailers is an essential phenomenon in modern marketing channels. Choi et al. [28] constructed a closed-loop supply chain decision model composed of a single manufacturer, retailer, and third-party recycler and studied the influence of dominance on the pricing strategy and recovery efficiency of the closed-loop supply chain. Dey and Giri [29] studied the influence of power structure differences on closed-loop supply chain pricing strategies under the background of a duopoly.

The other stream of relevant research to our paper mainly focuses on recycling channel choice. For example, Savaskan et al. [30] combined the actual situation faced by enterprises and studied recycling channel selection under the manufacturer leader. They modeled three recycling channels and found that retailer recycling is the best. Furthermore, Savaskan and Van Wassenhove [31] studied the impact of retailer competition on recycling channel choice on the basis of the literature [30]. Yi et al. [32] discussed the impact of recovery cost structure on reverse channel decision-making. The problem of how to distribute the recovery workload in a system with dual recovery channels was thus solved. Atasu et al. [33] discussed and proved how the recovery cost structure impacts the remanufacturer's reverse channel choice. Chuang et al. [34] studied the choice of reverse recycling channels for high-tech products with a short life cycle and unstable demand. Ma et al. [35] extended the works of Savaskan et al. [30] and studied the impact of the retailer marketing efforts and fairness concerns on recycling channels. The conclusion was consistent with the literature [30]; however, the service level of the retailer will improve the efficiency of the reverse channel. Giovanni et al. [36] studied the recycling channel selection of manufacturers under two cycles. They found that the manufacturer would only choose to outsource the recycling business to the retailer or the third-party recycler when the recovery cost of the manufacturer was high or when the efficiency of the recovery investment was low.

In recent years, the development of e-commerce has brought new opportunities and challenges to closed-loop supply chain management, which has attracted the attention of many scholars. The above studies on recycling channels are strictly limited to offline recycling channels and still call for further attention to this new trend. Feng et al. [1] noticed this trend early and established a comparison model of online and offline recycling channels. Considering consumer behavior, they researched the design and coordination of reverse supply chains with double recycling channels. Li et al. [2] expanded Feng's [1] model to study the impact of random product demand on the selection of online and offline recycling channels. In contrast, we consider the logistics service level of the e-commerce platform and the impact of the GAP effectiveness difference of recycling channels. Under 
the leadership of the e-commerce platform, we found some expected results through model construction, theoretical analysis, and experimental analysis.

\section{Problem Descriptions and Hypothesis}

All the notations in this paper are shown in Table 1.

Table 1. Summary of relevant notations.

\begin{tabular}{cl}
\hline Notation & \multicolumn{1}{c}{ Definition } \\
\hline$c_{n}$ & The unit cost of producing a new product \\
$c_{r}$ & The unit cost of producing a remanufactured product \\
$\Delta$ & The unit cost of producing a remanufactured product, $\Delta=c_{n}-c_{r}$ \\
$a$ & The variable payment to the consumer who returns one used product \\
$b$ & The transfer price paid by the manufacturer to the e-commerce \\
$\theta$ & Clatform or the third-party recycler for each used product \\
$\gamma$ & Consumer preference for online sales model \\
$\eta$ & Cost elasticity coefficient of logistics service level \\
$h$ & The consumer's response to the GAP which invested by the collector \\
$\delta$ & The profit of unit product \\
$w$ & The retail price of the product \\
$p$ & Logistics service level of the e-commerce platform \\
$s$ & The GAP composite index level determined by the collector \\
$A$ & The return rate of used products, $\tau=h A$ \\
$\tau$ & The optimal value for different models $(i=\mathrm{N}, \mathrm{M}, \mathrm{E}, \mathrm{T})$ \\
()$^{i *}$ & The profit of the system or member under different models \\
$\pi_{j}^{i}$ & $(i=\mathrm{N}, \mathrm{M}, \mathrm{E}, \mathrm{T} ; j=S C, M, E, T)$ \\
\hline
\end{tabular}

The ${ }^{*}$ sign represents the optimal profit or equilibrium strategies of the system members (the manufacturer, the e-commerce platform, and the third-party recycler).

\subsection{Problem Description}

We considered an E-CLSC consisting of a single manufacturer (M), e-commerce platform(E), and the consumer (C). The manufacturer produces new products and remanufactures used products and sells new products and remanufactured products to the e-commerce platform at the same wholesale price. The e-commerce platform uses "platform self-operated stores" to display and sell products and is responsible for product logistics services. By browsing the "platform self-run store," the consumer has a certain understanding of the product value and functions and finally considers whether to buy the product comprehensively according to the product sales price and logistics service level.

There are three recycling channels for the manufacturer to collect used products from the consumer in the market, namely the manufacturer recycling channel (Model M), the e-commerce platform recycling channel (Model E), and the third-party recycling channel (Model T). Figure 1 shows the structure in the research, where model $\mathrm{N}$ is the benchmark model, indicating that the manufacturer does not conduct used product recycling and remanufacturing activities. 


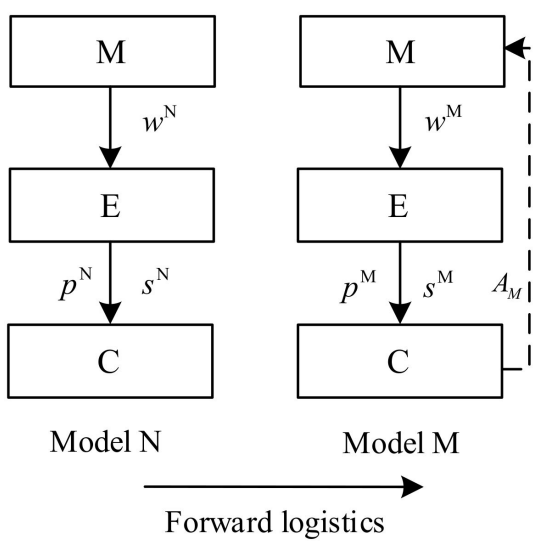

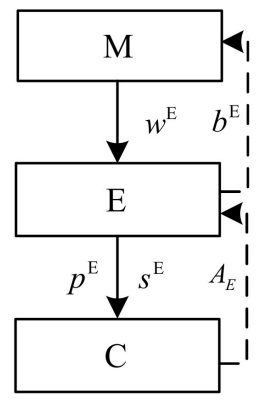

Model E

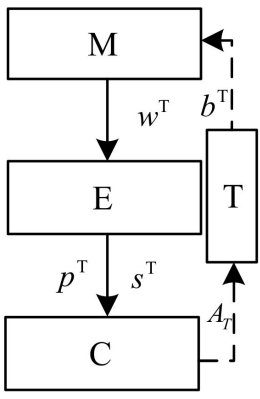

Model T

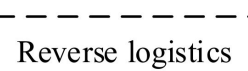

Figure 1. Structure of four models.

\subsection{Basic Hypothesis}

To better describe the problem, we made the following hypotheses:

Hypothesis 1. New products and remanufactured products are of the same quality, price and service.

Hypothesis 2. The manufacturer always can benefit from the remanufactured product., i.e., the production cost of the new product is higher than the cost of the remanufactured product.

Hypothesis 3 . The cost of the remanufactured product can result in more savings than the recycling price of the used product.

Hypothesis 4. The e-commerce platform is the leader, the decisions of the supply chain system is a single cycle, the members are rational, and the information is symmetric.

Hypothesis 5. For simplicity, we normalized the total market size to 1.

Hypothesis 6. Consumers are heterogeneous in the perceived value for products, and their perceived value is normalized and evenly distributed across the range [0,1].

Hypothesis 7. We consider a utility function depending on the consumer e-commerce platform channel preference (degree of trust), the product sales price, and the logistics service level: $u=\theta v-p+\gamma$ s. Based on consumer utility theory and Hypothesis 5, we can deduce that the product market demand function is

$$
q=1-\frac{p-\gamma s}{\theta}
$$

Similar to Ma et al. [35] and Giovanni et al. [36], the total logistics service cost is $\frac{1}{2} \eta s^{2}$, where $\eta$ is the cost elasticity coefficient of the logistics service level.

Hypothesis 8. The return rate can be influenced by the collector investing in green activity programs (GAP) such as the advertising and the promotion of their recycling policy, logistics service, staff training, etc., i.e., $\tau_{j}=h_{j} A_{j}$, where $A_{j}$ measures the intensity of the collector's investment in the recycling channel $j$ (the GAP comprehensive index level) and where $h_{j}$ is a positive scaling parameter measuring the consumer's response to these actions (the GAP effectiveness). The cost of $A_{j}$ is $A_{j}^{2} / 2$ (Giovanni et al. [36]). 
In order to ensure the existence of the product market, the following relationship should be satisfied among the model parameters:

1. $\theta>c_{n}$, which means that when $p=c_{n}, s=0$, the product market demand $q>0$.

2. $\theta \eta-\gamma^{2}>0$, which shows that the profit generated by improving the unit logistics service level is greater than the logistics service cost.

3. $c_{n}-h_{j}(\Delta-a)>0(j=M, E, T)$, which indicates that the production cost per unit product is greater than the revenue from recovery.

To simplify the expression, we let $G_{j}=\eta h_{j}^{2}(\Delta-a)^{2}$. It obvious that $\theta \eta-G_{j}>0$. When $h_{M}=h_{E}=h_{T}=h$, we have $G=\eta h^{2}(\Delta-a)^{2}$ and $\theta \eta-G>0$.

\section{Models and Results}

In this section, we will solve the optimization problem for each model and then derive the corresponding equilibrium strategies.

\subsection{E-Supply Chain Scenario (Model N)}

In model $\mathrm{N}$, the e-commerce platform first determines the unit product sales price $p^{\mathrm{N}}$ and logistics service level $s^{\mathrm{N}}$; then, the manufacturer decides the unit product wholesale price $w^{\mathrm{N}}$. Therefore, the profit functions of the manufacturer and the e-commerce platform are given by

$$
\begin{gathered}
\pi_{M}^{\mathrm{N}}=\left(w^{\mathrm{N}}-c_{n}\right)\left(1-\frac{p^{\mathrm{N}}-\gamma s^{\mathrm{N}}}{\theta}\right) \\
\pi_{E}^{\mathrm{N}}=\left(p^{\mathrm{N}}-w^{\mathrm{N}}\right)\left(1-\frac{p^{\mathrm{N}}-\gamma s^{\mathrm{N}}}{\theta}\right)-\frac{1}{2} \eta\left(s^{\mathrm{N}}\right)^{2}
\end{gathered}
$$

Lemma 1. The profit function $\pi_{M}^{N}$ is strictly concave in $w^{N}$.

Proof. See Appendix A. Similar to lemma 1, the following proof process of all of the lemmas and the propositions will be omitted in this paper. See the Appendix A for the specific proof process.

Proposition 1. In model $N$, the optimal decisions and demand are given by

$$
\begin{aligned}
w^{\mathrm{N}^{*}}=\frac{\theta^{2} \eta+3 \theta \eta c_{n}-\gamma^{2} c_{n}}{4 \theta \eta-\gamma^{2}}, p^{\mathrm{N}^{*}} & =\frac{3 \theta^{2} \eta+\theta \eta c_{n}-\gamma^{2} c_{n}}{4 \theta \eta-\gamma^{2}}, s^{\mathrm{N} *}=\frac{\gamma\left(\theta-c_{n}\right)}{4 \theta \eta-\gamma^{2}} \\
, q^{\mathrm{N}^{*}} & =\frac{\eta\left(\theta-c_{n}\right)}{4 \theta \eta-\gamma^{2}} .
\end{aligned}
$$

The corresponding profits of the manufacturer, the e-commerce platform, and the system are as follows:

$$
\pi_{M}^{\mathrm{N}^{*}}=\frac{\theta \eta^{2}\left(\theta-c_{n}\right)^{2}}{\left(4 \theta \eta-\gamma^{2}\right)^{2}}, \pi_{E}^{\mathrm{N}^{*}}=\frac{\eta\left(\theta-c_{n}\right)^{2}}{2\left(4 \theta \eta-\gamma^{2}\right)}, \pi_{S C}^{\mathrm{N}^{*}}=\frac{\eta\left(6 \theta \eta-\gamma^{2}\right)\left(\theta-c_{n}\right)^{2}}{2\left(4 \theta \eta-\gamma^{2}\right)^{2}} .
$$

\subsection{The Manufacturer Collects the Used Products (Model M)}

In model $\mathrm{M}$, the e-commerce platform first determines the product sales price $p^{\mathrm{M}}$ and logistics service level $s^{\mathrm{M}}$, based on which the manufacturer decides the product wholesale 
price $w^{\mathrm{M}}$ and the GAP comprehensive index level $A_{M}$. Therefore, the profit functions of the manufacturer and the e-commerce platform are given by

$$
\begin{gathered}
\pi_{M}^{\mathrm{M}}=\left(w^{\mathrm{M}}-c_{n}+(\Delta-a) h_{M} A_{M}\right)\left(1-\frac{p^{\mathrm{M}}-\gamma s^{\mathrm{M}}}{\theta}\right)-\frac{1}{2}\left(A_{M}\right)^{2} \\
\pi_{E}^{\mathrm{M}}=\left(p^{\mathrm{M}}-w^{\mathrm{M}}\right)\left(1-\frac{p^{\mathrm{M}}-\gamma s^{\mathrm{M}}}{\theta}\right)-\frac{1}{2} \eta\left(s^{\mathrm{M}}\right)^{2}
\end{gathered}
$$

Lemma 2. The profit function $\pi_{M}^{M}$ is strictly concave in $w^{M}$ and $A_{M}$.

Proposition 2. In model $M$, the optimal decisions and demand are given by

$$
\begin{gathered}
A_{M}^{*}=\frac{\eta h_{M}(\Delta-a)\left(\theta-c_{n}\right)}{4 \theta \eta-\gamma^{2}-2 G_{M}}, w^{\mathrm{M}^{*}}=\frac{\theta\left(\theta \eta-G_{M}\right)+c_{n}\left(3 \theta \eta-\gamma^{2}-G_{M}\right)}{4 \theta \eta-\gamma^{2}-2 G_{M}}, \\
p^{\mathrm{M}^{*}}=\frac{\theta\left(3 \theta \eta-2 G_{M}\right)+c_{n}\left(\theta \eta-\gamma^{2}\right)}{4 \theta \eta-\gamma^{2}-2 G_{M}}, s^{\mathrm{M}^{*}}=\frac{\gamma\left(\theta-c_{n}\right)}{4 \theta \eta-\gamma^{2}-2 G_{M}}, \\
q^{\mathrm{M}^{*}}=\frac{\eta\left(\theta-c_{n}\right)}{4 \theta \eta-\gamma^{2}-2 G_{M}} .
\end{gathered}
$$

The corresponding profits of the manufacturer, the e-commerce platform, and the system are as follows:

$$
\begin{gathered}
\pi_{M}^{\mathrm{M}^{*}}=\frac{\eta\left(\theta-c_{n}\right)^{2}\left(2 \theta \eta-G_{M}\right)}{2\left(4 \theta \eta-\gamma^{2}-2 G_{M}\right)^{2}}, \pi_{E}^{\mathrm{M}^{*}}=\frac{\eta\left(\theta-c_{n}\right)^{2}}{2\left(4 \theta \eta-\gamma^{2}-2 G_{M}\right)}, \\
\pi_{S C}^{\mathrm{M}^{*}}=\frac{\eta\left(\theta-c_{n}\right)^{2}\left(6 \theta \eta-\gamma^{2}-3 G_{M}\right)}{2\left(4 \theta \eta-\gamma^{2}-2 G_{M}\right)^{2}}
\end{gathered}
$$

\subsection{The E-Commerce Platform Collects the Used Products (Model E)}

In model $\mathrm{E}$, the e-commerce platform first determines the product sales price $p^{\mathrm{E}}$, logistics service level $s^{\mathrm{E}}$, and GAP comprehensive index level $A_{E}$; then, the manufacturer decides the product wholesale price $w^{\mathrm{E}}$ and the used product transfer price $b^{\mathrm{E}}$. Therefore, the profit functions of the manufacturer and the e-commerce platform are given by

$$
\begin{gathered}
\pi_{M}^{\mathrm{E}}=\left(w^{\mathrm{E}}-c_{n}+\left(\Delta-b^{\mathrm{E}}\right) h_{E} A_{E}\right)\left(1-\frac{p^{\mathrm{E}}-\gamma s^{\mathrm{E}}}{\theta}\right) \\
\pi_{E}^{\mathrm{E}}=\left(p^{\mathrm{E}}-w^{\mathrm{E}}+\left(b^{\mathrm{E}}-a\right) h_{E} A_{E}\right)\left(1-\frac{p^{\mathrm{E}}-\gamma s^{\mathrm{E}}}{\theta}\right)-\frac{1}{2} \eta\left(s^{\mathrm{E}}\right)^{2}-\frac{1}{2}\left(A_{E}\right)^{2}
\end{gathered}
$$

Lemma 3. For any given used product transfer price $b^{E}$, the profit function $\pi_{M}^{E}$ is strictly concave in $w^{E}$. 
Proposition 3. In model E, the optimal decisions and demand are given by

$$
\begin{aligned}
& A_{E}^{*}=\frac{\eta h_{E}(\Delta-a)\left(\theta-c_{n}\right)}{4 \theta \eta-\gamma^{2}-G_{E}}, \\
& w^{\mathrm{E}^{*}}=\frac{\theta \eta\left(\theta-h_{E}^{2}(\Delta-a)\left(\Delta-b^{\mathrm{E}}\right)\right)+c_{n}\left(3 \theta \eta-\gamma^{2}-\eta h_{E}^{2}(\Delta-a)\left(b^{\mathrm{E}}-a\right)\right)}{4 \theta \eta-\gamma^{2}-G_{E}}, \\
& p^{\mathrm{E}^{*}}=\frac{\theta \eta\left(3 \theta-h_{E}^{2}(\Delta-a)^{2}\right)+c_{n}\left(\theta \eta-\gamma^{2}\right)}{4 \theta \eta-\gamma^{2}-G_{E}}, s^{\mathrm{E}^{*}}=\frac{\gamma\left(\theta-c_{n}\right)}{4 \theta \eta-\gamma^{2}-G_{E}}, \\
& q^{\mathrm{E}^{*}}=\frac{\eta\left(\theta-c_{n}\right)}{4 \theta \eta-\gamma^{2}-G_{E}}
\end{aligned}
$$

The corresponding profits of the manufacturer, the e-commerce platform, and the system are as follows:

$$
\begin{gathered}
\pi_{M}^{\mathrm{E}^{*}}=\frac{\theta \eta^{2}\left(\theta-c_{n}\right)^{2}}{\left(4 \theta \eta-\gamma^{2}-G_{E}\right)^{2}}, \pi_{E}^{\mathrm{E}^{*}}=\frac{\eta\left(\theta-c_{n}\right)^{2}}{2\left(4 \theta \eta-\gamma^{2}-G_{E}\right)}, \\
\pi_{S C}^{\mathrm{E}^{*}}=\frac{\eta\left(\theta-c_{n}\right)^{2}\left(6 \theta \eta-\gamma^{2}-G_{E}\right)}{2\left(4 \theta \eta-\gamma^{2}-G_{E}\right)^{2}} .
\end{gathered}
$$

Observation 1. The manufacturer's profit is not affected by the transfer price of used products.

\subsection{The Third-Party Recycler Collects the Used Products (Model T)}

In model $\mathrm{T}$, the e-commerce platform first determines the product sales price $p^{\mathrm{T}}$ and logistics service level $s^{\mathrm{T}}$; then, the manufacturer decides the product wholesale price $w^{\mathrm{T}}$ and the used product transfer price $b^{\mathrm{T}}$ accordingly. Finally, the third-party recycler decides the GAP comprehensive index level $A_{T}$ according to the decision of the manufacturer and the e-commerce platform. Therefore, the profit functions of the manufacturer, the e-commerce platform, and the third-party recycler are given by

$$
\begin{gathered}
\pi_{M}^{\mathrm{T}}=\left(w^{\mathrm{T}}-c_{n}+\left(\Delta-b^{\mathrm{T}}\right) h_{T} A_{T}\right)\left(1-\frac{p^{\mathrm{T}}-\gamma s^{\mathrm{T}}}{\theta}\right) \\
\pi_{E}^{\mathrm{T}}=\left(p^{\mathrm{T}}-w^{\mathrm{T}}\right)\left(1-\frac{p^{\mathrm{T}}-\gamma s^{\mathrm{T}}}{\theta}\right)-\frac{1}{2} \eta\left(s^{\mathrm{T}}\right)^{2} \\
\pi_{T}^{\mathrm{T}}=\left(b^{\mathrm{T}}-a\right) h_{T} A_{T}\left(1-\frac{p^{\mathrm{T}}-\gamma s^{\mathrm{T}}}{\theta}\right)-\frac{1}{2}\left(A_{T}\right)^{2}
\end{gathered}
$$

Lemma 4. The function $\pi_{T}^{T}$ and $\pi_{M}^{T}$, respectively, are strictly concave in $A_{T}$ and $w^{T}$. 
Proposition 4. In model T, the optimal decisions and demand are given by

$$
\begin{gathered}
w^{\mathrm{T}^{*}}=\frac{\theta \eta\left(\theta-2 h_{T}^{2}\left(\Delta-b^{\mathrm{T}}\right)\left(b^{\mathrm{T}}-a\right)\right)+c_{n}\left(3 \theta \eta-\gamma^{2}-2 \eta h_{T}^{2}\left(\Delta-b^{\mathrm{T}}\right)\left(b^{\mathrm{T}}-a\right)\right)}{4 \theta \eta-\gamma^{2}-4 \eta h_{T}^{2}\left(\Delta-b^{\mathrm{T}}\right)\left(b^{\mathrm{T}}-a\right)}, \\
p^{\mathrm{T}^{*}}=\frac{\theta \eta\left(3 \theta-4 h_{T}^{2}\left(\Delta-b^{\mathrm{T}}\right)\left(b^{\mathrm{T}}-a\right)\right)+c_{n}\left(\theta \eta-\gamma^{2}\right)}{4 \theta \eta-\gamma^{2}-4 \eta h_{T}^{2}\left(\Delta-b^{\mathrm{T}}\right)\left(b^{\mathrm{T}}-a\right)}, \\
s^{\mathrm{T}^{*}}=\frac{\gamma\left(\theta-c_{n}\right)}{4 \theta \eta-\gamma^{2}-4 \eta h_{T}^{2}\left(\Delta-b^{\mathrm{T}}\right)\left(b^{\mathrm{T}}-a\right)}, \\
A_{T}^{*}=\frac{\eta h_{T}\left(b^{\mathrm{T}}-a\right)\left(\theta-c_{n}\right)}{4 \theta \eta-\gamma^{2}-4 \eta h_{T}^{2}\left(\Delta-b^{\mathrm{T}}\right)\left(b^{\mathrm{T}}-a\right)}, \\
q^{\mathrm{T}^{*}}=\frac{\eta\left(\theta-c_{n}\right)}{4 \theta \eta-\gamma^{2}-4 \eta h_{T}^{2}\left(\Delta-b^{\mathrm{T}}\right)\left(b^{\mathrm{T}}-a\right)} .
\end{gathered}
$$

The corresponding profits of the manufacturer, the e-commerce platform, the third-party recycler, and the system are as follows:

$$
\begin{gathered}
\pi_{M}^{\mathrm{T}^{*}}=\frac{\eta^{2}\left(\theta-c_{n}\right)^{2}\left(\theta-h_{T}^{2}\left(\Delta-b^{\mathrm{T}}\right)\left(b^{\mathrm{T}}-a\right)\right)}{\left(4 \theta \eta-\gamma^{2}-4 \eta h_{T}^{2}\left(\Delta-b^{\mathrm{T}}\right)\left(b^{\mathrm{T}}-a\right)\right)^{2}}, \\
\pi_{E}^{\mathrm{T}^{*}}=\frac{\eta\left(\theta-c_{n}\right)^{2}}{2\left(4 \theta \eta-\gamma^{2}-4 \eta h_{T}^{2}\left(\Delta-b^{\mathrm{T}}\right)\left(b^{\mathrm{T}}-a\right)\right)^{\prime}} \\
\pi_{T}^{\mathrm{T}^{*}}=\frac{\eta^{2} h_{T}^{2}\left(b^{\mathrm{T}}-a\right)^{2}\left(\theta-c_{n}\right)^{2}}{2\left(4 \theta \eta-\gamma^{2}-4 \eta h_{T}^{2}\left(\Delta-b^{\mathrm{T}}\right)\left(b^{\mathrm{T}}-a\right)\right)^{2}} \\
\pi_{S C}^{\mathrm{T}^{*}}=\frac{\eta\left(\theta-c_{n}\right)^{2}\left(6 \theta \eta-\gamma^{2}-\eta h_{T}^{2}\left(6 \Delta-7 b^{\mathrm{T}}+a\right)\left(b^{\mathrm{T}}-a\right)\right)}{2\left(4 \theta \eta-\gamma^{2}-4 \eta h_{T}^{2}\left(\Delta-b^{\mathrm{T}}\right)\left(b^{\mathrm{T}}-a\right)\right)^{2}} .
\end{gathered}
$$

Observation 2. When $b^{T^{*}}=\frac{\Delta+a}{2}$, the manufacturer's profit function is maximum.

\section{Comparisons and Analyses}

5.1. Comparisons of the Four Different Models

By comparing the equilibrium strategies and profits of system members under the four different models, we achieve the following propositions.

Proposition 5. The optimal GAP comprehensive index level satisfies the following relationship: $\partial A_{j}^{*} / \partial h_{j}>0(j=M, E, T)$, If $h_{M}=h_{E}=h_{T}$, we get $A_{M}^{*}>A_{E}^{*}>A_{T}^{*}$.

To illustrate above results, we present the following, Figure 2 (we set $c_{n}=0.4, \Delta=0.2$, $a=0.01, \gamma=0.7, \eta=1$. These parameters will be adopted throughout this paper.), showing how the GAP effectiveness affects the GAP comprehensive index level. 


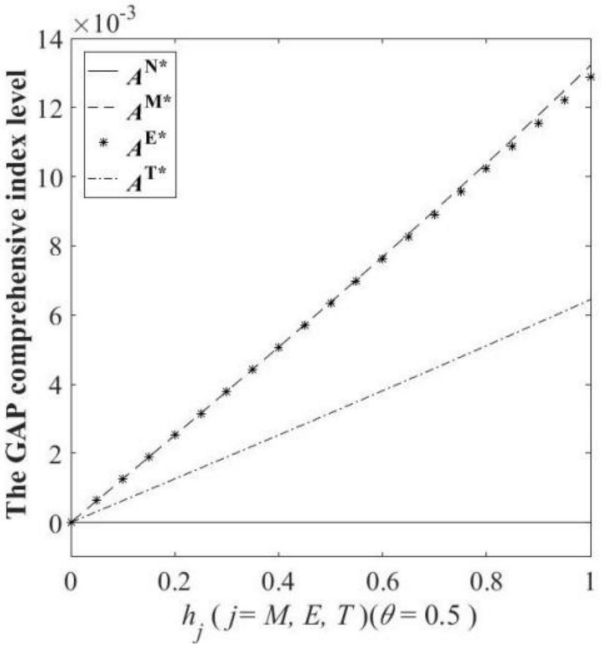

(a)

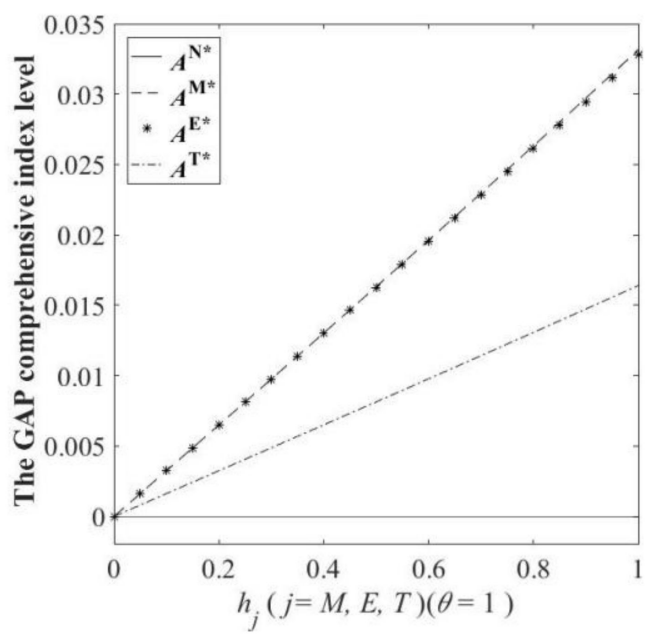

(b)

Figure 2. Relationship between the GAP composite index level and GAP effectiveness.

Proposition 5 shows that the GAP comprehensive index level increases with the increase of the GAP effectiveness. If $h_{M}=h_{E}=h_{T}$; then, the optimal GAP comprehensive index level under model $\mathrm{M}$ is the best, followed by the $\mathrm{E}$ collection and, lastly, the $\mathrm{T}$ collection. This is because the only way that the third-party recycler can influence market demand to improve its profitability is to invest in GAP. However, the manufacturer can not only directly decide the GAP investment, but this can also be achieved through the wholesale price of the indirect impact of the GAP comprehensive index level.

As seen in Figure $2 a(\theta=0.5)$ and Figure $2 b(\theta=1)$, the increase of consumer channel preference will help to improve the GAP composite index level, and there is no significant difference between model $\mathrm{M}$ and model $\mathrm{E}$ in the GAP comprehensive index level, but they are significantly higher than model T. With the increase of GAP effectiveness, the gap of the GAP comprehensive index level becomes larger and larger.

Proposition 6. The optimal product sales price satisfies the following relationship: $\partial p^{\mathrm{M}^{*}} / \partial h_{M}<0$, $\partial p^{E^{*}} / \partial h_{E}<0, \partial p^{T^{*}} / \partial h_{T}<0$. If $h_{M}=h_{E}=h_{T}$, we get $p^{\mathrm{N}^{*}}>p^{T^{*}}=p^{E^{*}}>p^{\mathrm{M}^{*}}$.

In order to show the result intuitively, we also present the following figure, Figure 3, showing how the GAP effectiveness affects the product sales price.

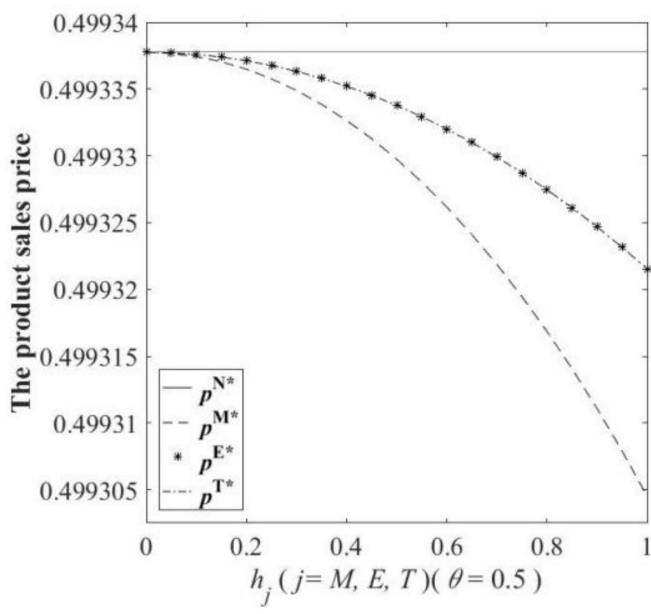

(a)

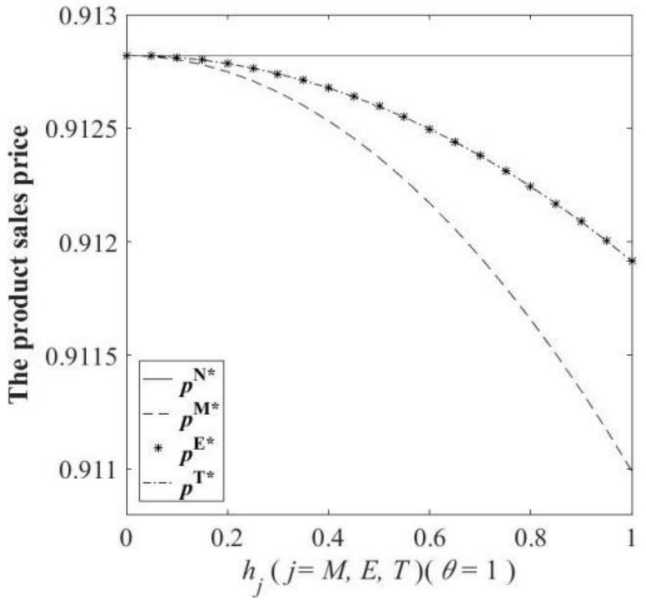

(b)

Figure 3. Relationship between the product sales price and GAP effectiveness. 
Proposition 6 indicates that the product sales price decreases with the increase of the GAP effectiveness. If $h_{M}=h_{E}=h_{T}$, then the optimal product sales price under model M is the lowest, followed by model $\mathrm{E}$ and $\mathrm{T}$, and the highest is in model $\mathrm{N}$. The reason for this is that the average production cost of products can be reduced by remanufacturing. In model $\mathrm{E}$ and model $\mathrm{T}$, the sales price of the product is the same, which illustrates that compared with model $\mathrm{M}$, in model $\mathrm{E}$ and $\mathrm{T}$, the e-commerce platform does not change the product sales price.

According to Figure $3 a(\theta=0.5)$ and Figure $3 b(\theta=1)$, we found that the increase of consumer channel preference will help to improve the product sales price, and there is no significant difference among any of the models in terms of the product sales price. However, with the increase of GAP effectiveness, the difference becomes bigger and bigger.

Proposition 7. The optimal logistics service level satisfies the following relationship: $\partial s^{\mathrm{M}^{*}} / \partial h_{M}>0$, $\partial s^{\mathrm{E}^{*}} / \partial h_{E}>0, \partial s^{\mathrm{T}^{*}} / \partial h_{T}>0$. If $h_{M}=h_{E}=h_{T}$, we get $s^{\mathrm{M}^{*}}>s^{\mathrm{E}^{*}}=s^{\mathrm{T}^{*}}>s^{\mathrm{N}^{*}}$.

Next, we also present the following figure, Figure 4, which shows how the GAP effectiveness affects the logistics service level.

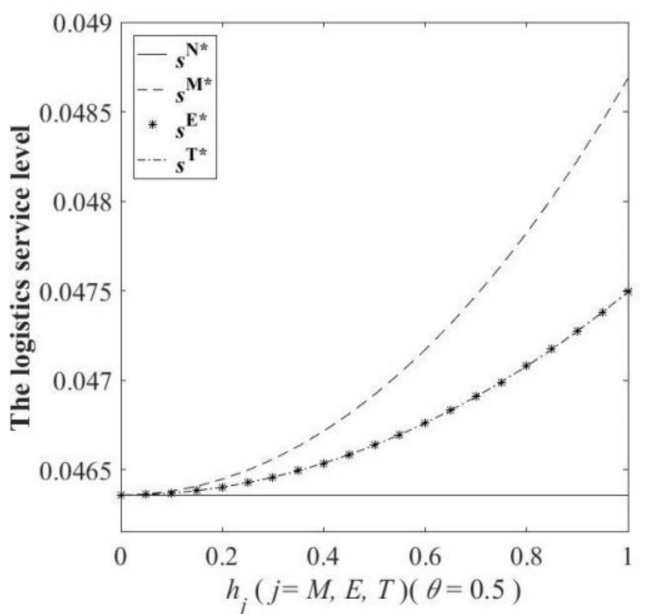

(a)

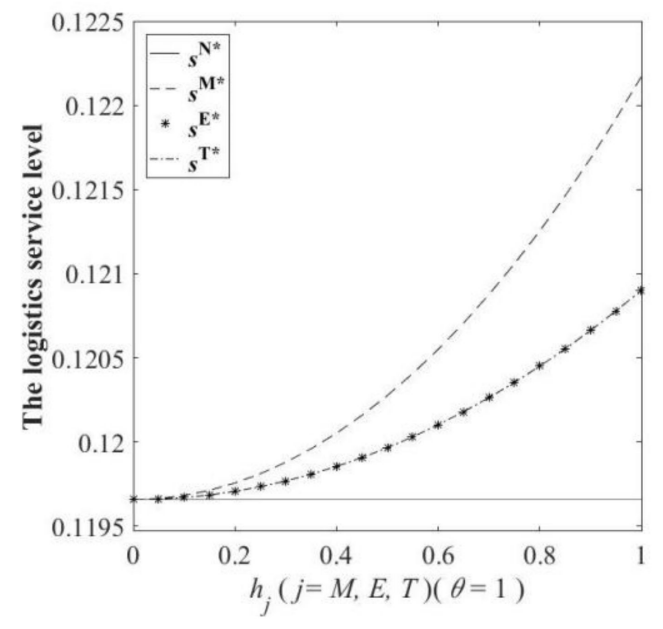

(b)

Figure 4. Relationship between the logistics service level and GAP effectiveness.

Proposition 7 illustrates that the logistics service level increases with the increase of the GAP effectiveness. Different from Proposition 6, if $h_{M}=h_{E}=h_{T}$, the optimal logistics service level under model $\mathrm{M}$ is the highest, followed by model $\mathrm{E}$ and $\mathrm{T}$, and the lowest is in model $\mathrm{N}$. This is because the e-commerce platform will set a logistics service level that matches the product sales price in order to maximize profits.

Similar Proposition 5 and Proposition 6, which are depicted in Figure $4 \mathrm{a}(\theta=0.5)$ and Figure $4 \mathrm{~b}(\theta=1)$, tell us that the increase of the consumer channel preference also will help to improve the logistics service level, and there are no significant differences among any of the models. However, with the increase of GAP effectiveness, the difference becomes bigger and bigger.

Proposition 8. The product market demand satisfies the following relationship: $\partial q^{\mathrm{M}^{*}} / \partial h_{M}>0$, $\partial q^{\mathrm{E}^{*}} / \partial h_{E}>0, \partial q^{\mathrm{T}^{*}} / \partial h_{T}>0$. If $h_{M}=h_{E}=h_{T}$, we get $q^{\mathrm{M}^{*}}>q^{\mathrm{E}^{*}}=q^{\mathrm{T} *}>q^{\mathrm{N}^{*}}$.

In order to visualize the above results, we present the following figure, Figure 5, which shoes how the GAP effectiveness affects the product market demand. 


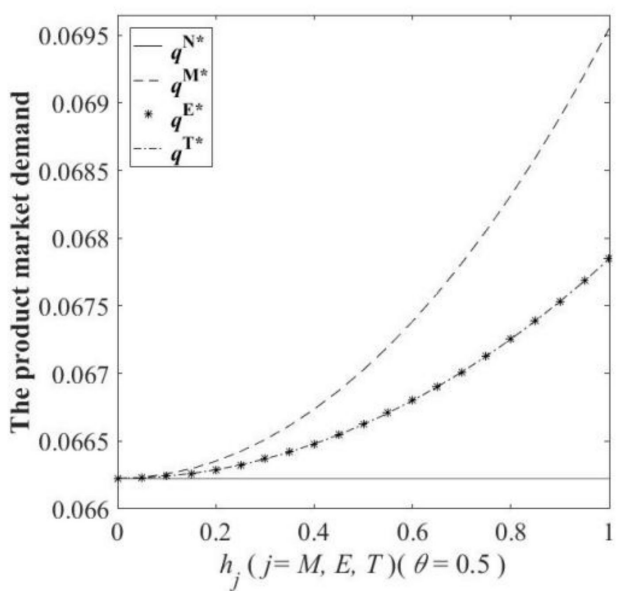

(a)

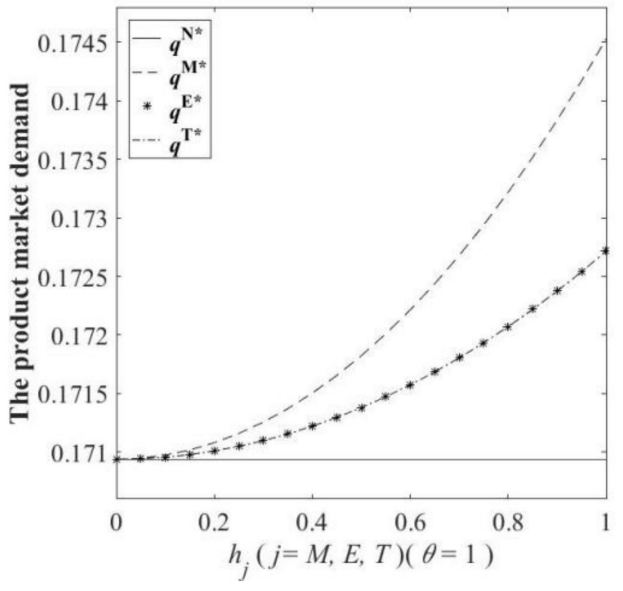

(b)

Figure 5. Relationship between the product market demand and GAP effectiveness.

Proposition 8 verifies Proposition 6 and Proposition 7, which demonstrates that the product market demand increases with the increase of GAP effectiveness. Similar to Proposition 7, if $h_{M}=h_{E}=h_{T}$, then the optimal product market demand under model M is the highest, followed by model $\mathrm{E}$ and $\mathrm{T}$, and the lowest is in model $\mathrm{N}$. This is because the product market demand depends on product sales price and logistics service level and is negatively correlated with product sales price and is positively correlated with logistics service level.

By comparing Figure $5 a(\theta=0.5)$ and Figure $5 b(\theta=1)$, we found that the increase of consumer channel preference will also help to improve the product market demand, and there are no significant differences among any of the models. However, with the increase of GAP effectiveness, the difference becomes bigger and bigger.

Proposition 9. The manufacturer's profit satisfies the following relationship: $\partial \pi_{M}^{\mathrm{M}^{*}} / \partial h_{M}>0$, $\partial \pi_{M}^{\mathrm{E}^{*}} / \partial h_{E}>0, \partial \pi_{M}^{\mathrm{T}^{*}} / \partial h_{T}>0$. If $h_{M}=h_{E}=h_{T}$, we get $\pi_{M}^{\mathrm{M}^{*}}>\pi_{M}^{\mathrm{E}^{*}}>\pi_{M}^{\mathrm{T}^{*}}>\pi_{M}^{\mathrm{N}^{*}}$.

Again, we present the following figure, Figure 6, which shows how the GAP effectiveness affects the manufacturer's profit.

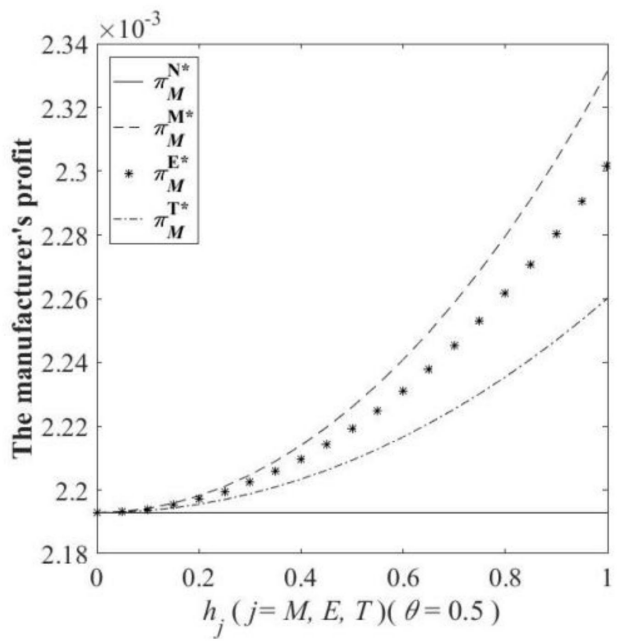

(a)

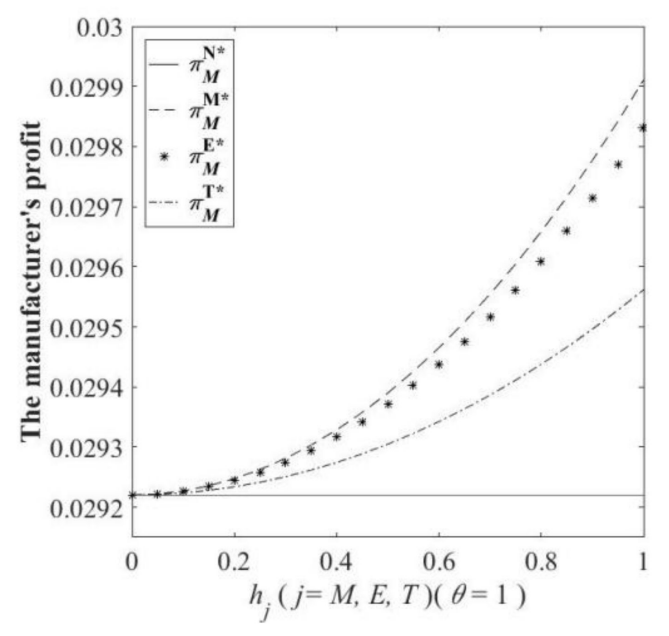

(b)

Figure 6. Relationship between the manufacturer's profit and GAP effectiveness. 
Proposition 9 confirms that the manufacturer's profit increases with the increase of the GAP effectiveness. The profit of the manufacturer under remanufacturing is higher than that under a no manufacturing scenario. By comparing model $\mathrm{M}$, model $\mathrm{E}$, and model T, it can be determined that if $h_{M}=h_{E}=h_{T}$, then the optimal manufacturer's profit under model $\mathrm{M}$ is the highest, followed by model $\mathrm{E}$, and the lowest is in model T. The reason for this is that the manufacturer can obtain all of the profits of the reverse channel in model $\mathrm{M}$, and the participation of third-party recyclers will amplify the impact of the double margin effect.

From Figure $6 a(\theta=0.5)$ and Figure $6 \mathrm{~b}(\theta=1)$, we found that the increase of consumer channel preference will also help to improve the manufacturer's profit, and there are no significant differences among any of the models. However, with the increase of GAP effectiveness, the difference becomes bigger and bigger.

Proposition 10. The e-commerce platform's profit satisfies the following relationship: $\partial \pi_{E}^{\mathrm{M}^{*}} / \partial h_{M}>0$, $\partial \pi_{E}^{\mathrm{E}^{*}} / \partial h_{E}>0, \partial \pi_{E}^{\mathrm{T}^{*}} / \partial h_{T}>0$. If $h_{M}=h_{E}=h_{T}$, we get $\pi_{E}^{\mathrm{M}^{*}}>\pi_{E}^{\mathrm{E}^{*}}=\pi_{E}^{\mathrm{T}^{*}}>\pi_{E}^{\mathrm{N}^{*}}$.

Similarly, in Proposition 10, we also present the following figure, Figure 7, which shows how the GAP effectiveness affects the e-commerce platform's profit.

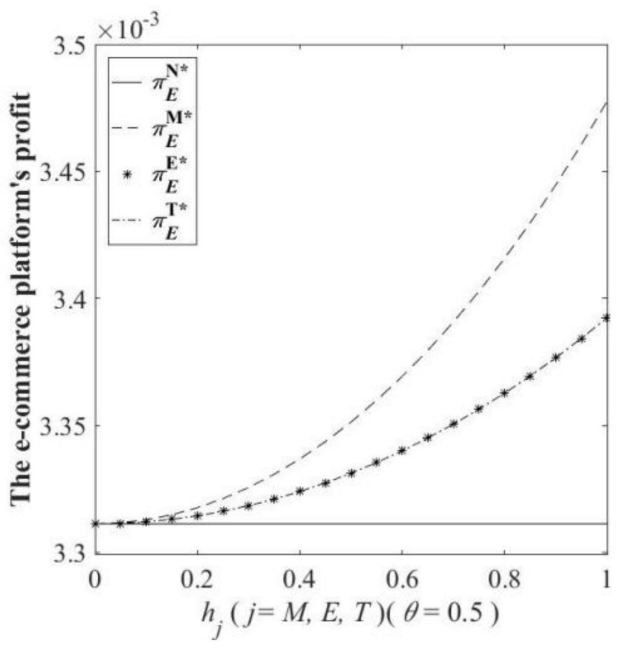

(a)

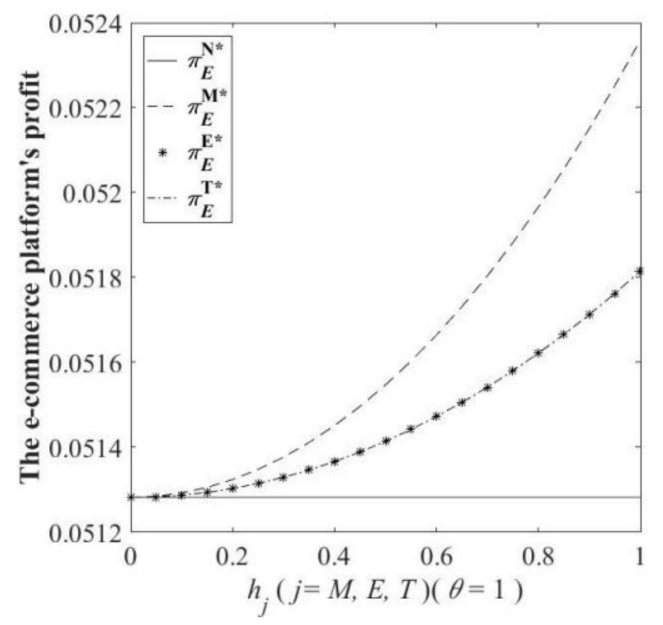

(b)

Figure 7. Relationship between the e-commerce platform's profit and GAP effectiveness.

Proposition 10 establishes that the e-commerce platform's profit increases with the increase of the GAP effectiveness. By comparing model $\mathrm{N}$, model $\mathrm{M}$, model $\mathrm{E}$, and model $\mathrm{T}$, it can be obtained that if $h_{M}=h_{E}=h_{T}$, then the optimal e-commerce platform's profit under model $\mathrm{M}$ is the highest, followed by model $\mathrm{E}$ and $\mathrm{T}$, and the lowest is in model $\mathrm{N}$. The reason for this is that the e-commerce platform is the leader of the E-CLSC and the participation of the third-party recycler does not affect the maximum profit.

From Figure $7 \mathrm{a}(\theta=0.5)$ and Figure $7 \mathrm{~b}(\theta=1)$, we found that the increase of consumer channel preference also will help to improve the e-commerce platform's profit, and there are no significant differences among any of the models. Similarly, with the increase of GAP effectiveness, the difference becomes bigger and bigger.

Proposition 11. The system's profit also satisfies the following relationship: $\partial \pi_{S C}^{\mathrm{M}^{*}} / \partial h_{M}>0$, $\partial \pi_{S C}^{\mathrm{E}^{*}} / \partial h_{E}>0, \partial \pi_{S C}^{\mathrm{T}^{*}} / \partial h_{T}>0$. If $h_{M}=h_{E}=h_{T}$, we get $\pi_{S C}^{\mathrm{M}^{*}}>\pi_{S C}^{\mathrm{E}^{*}}>\pi_{S C}^{\mathrm{T}^{*}}>\pi_{S C}^{\mathrm{N}^{*}}$.

To directly show the above results, we present the following figure, Figure 8, which shows how the GAP effectiveness affects the system's profit. 


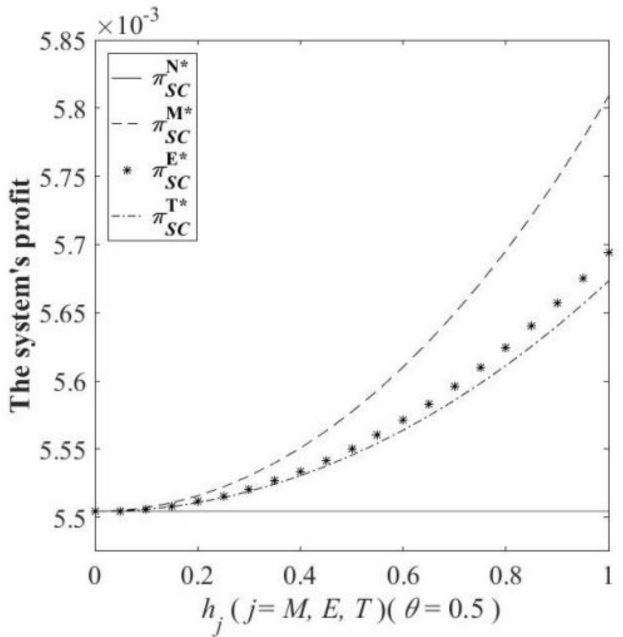

(a)

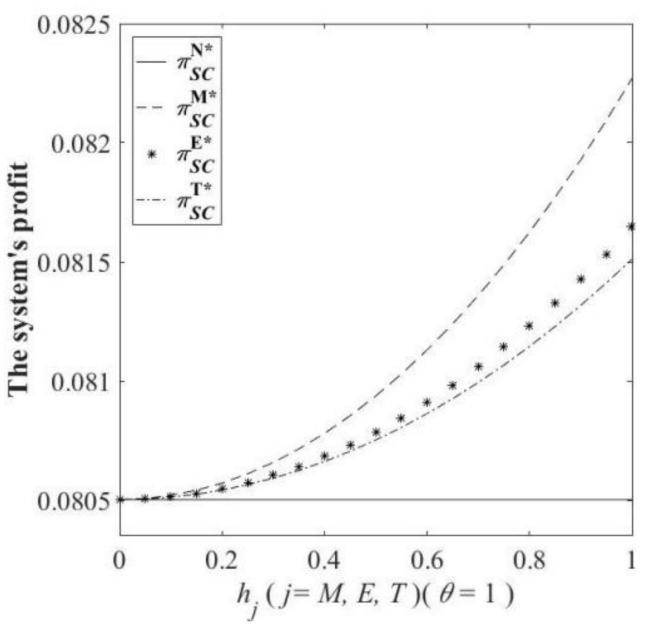

(b)

Figure 8. Relationship between the system's profit and GAP effectiveness.

From Proposition 11, we found that the system's profit increases with the increase of the GAP effectiveness. Similar to Proposition 9, the profit of the system under remanufacturing is higher than when it is under a no manufacturing scenario. Comparing model $\mathrm{M}$, model E, and model T, we can deduce that if $h_{M}=h_{E}=h_{T}$, then the optimal system's profit under model $\mathrm{M}$ is the highest, followed by model $\mathrm{E}$, and the lowest is in model $\mathrm{T}$. The reason for this is that the system is the is the sum of the profits of system members. The participation of third-party recyclers not only affects the profits of manufacturers but also affects the profit of the system.

Comparing Figure $8 \mathbf{a}(\theta=0.5)$ and Figure $8 \mathbf{b}(\theta=1)$, we can see that the increase of consumer channel preference will also help to improve the system's profit, and there are no significant differences among any of the models. Similarly, with the increase of GAP effectiveness, the difference becomes bigger and bigger. The system's profit gap in model E and model $\mathrm{T}$ is smaller than that of the other models.

Proposition 12. The manufacturer's margin profit satisfies the following relationship: $\partial \delta_{M}^{\mathrm{M}^{*}} / \partial h_{M}>0$, $\partial \delta_{M}^{\mathrm{E}^{*}} / \partial h_{E}>0, \partial \delta_{M}^{\mathrm{T}^{*}} / \partial h_{T}>0$. If $h_{M}=h_{E}=h_{T}$, we get $\delta_{M}^{\mathrm{E}^{*}}>\delta_{M}^{\mathrm{M}^{*}}>\delta_{M}^{\mathrm{T}^{*}}>\delta_{M}^{\mathrm{N}^{*}}$. However, the e-commerce platform's margin profit satisfies the following relationship: $\partial \delta_{E}^{\mathrm{M}^{*}} / \partial h_{M}=\partial \delta_{E}^{\mathrm{E}^{*}} / \partial h_{E}=$ $\partial \delta_{E}^{\mathrm{T}^{*}} / \partial h_{T}=0$. If $h_{M}=h_{E}=h_{T}$, we get $\delta_{E}^{\mathrm{N}^{*}}=\delta_{E}^{\mathrm{M}^{*}}=\delta_{E}^{\mathrm{E}^{*}}=\delta_{E}^{\mathrm{T}^{*}}=\frac{\theta-c_{n}}{2}$.

Next, we also present the following figure, Figure 9, which shows how the GAP effectiveness affects the manufacturer's margin profit.

Proposition 12 shows that the manufacturer's margin profit increases with the increase of the GAP effectiveness, but the e-commerce platform 's margin profit has nothing to do with the GAP effectiveness. Similar to Proposition 9, the manufacturer's profit margin under remanufacturing is higher than that under a no manufacturing scenario. However, comparing model M, model, E and model T, we can determine that if $h_{M}=h_{E}=h_{T}$, then the optimal manufacturer's margin profit under model $\mathrm{E}$ is the highest, followed by model $\mathrm{M}$, and the lowest is in model T. 


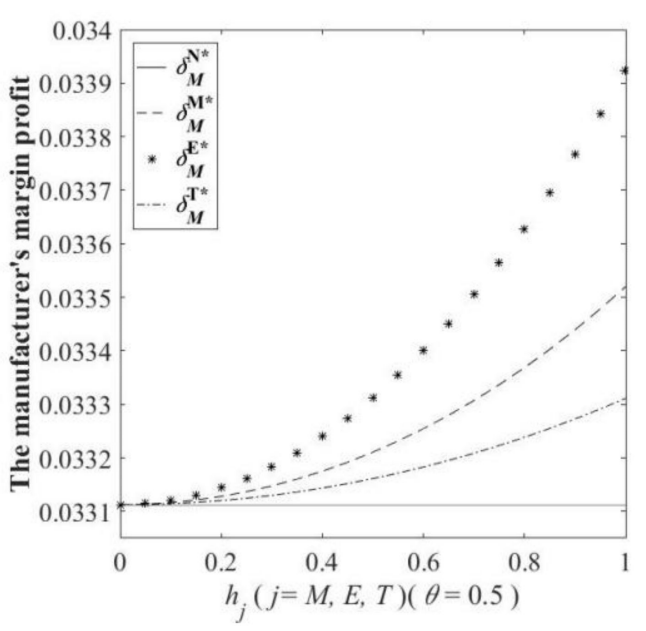

(a)

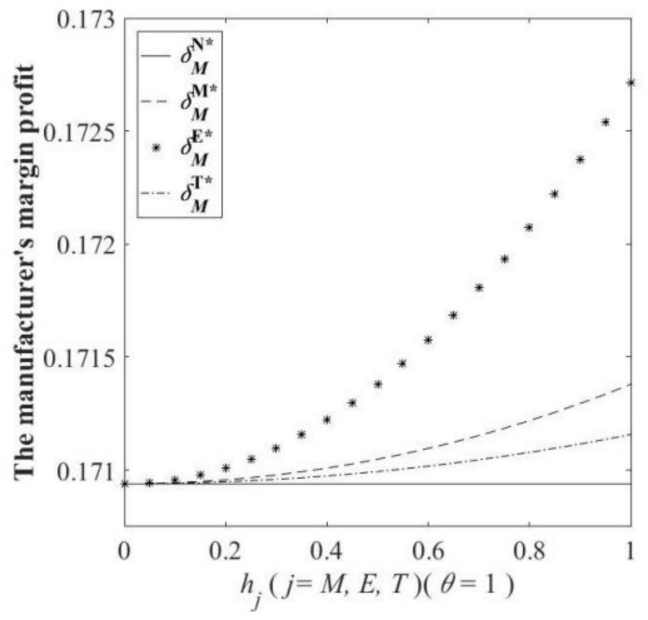

(b)

Figure 9. Relationship between the manufacturer's margin profit and GAP effectiveness.

Comparing Figure $9 \mathrm{a}(\theta=0.5)$ and Figure $9 \mathrm{~b}(\theta=1)$, we can determine that increasing the consumer channel preference will also help to improve the manufacturer's margin profit, and there are no significant differences among any of the models. Similarly, with the increase of the GAP effectiveness, the difference becomes bigger and bigger.

Corollary 1. The profit per unit product of the manufacturer and the e-commerce platform is as follows: $\delta_{E}^{i}>\delta_{M}^{i}(i=\mathrm{M}, \mathrm{E}, \mathrm{T}, \mathrm{N})$.

\subsection{Impact of Model Parameters on Equilibrium Strategies and Profits}

Next, we studied the effect of the logistics service utility elasticity coefficient and the logistics service cost elasticity coefficient on equilibrium strategies and profits.

Proposition 13. The impact of the logistics service utility elasticity coefficient on the equilibrium strategies and profits of the manufacturer and the e-commerce platform is as follows: (1) $\frac{\partial A_{j}^{*}}{\partial \gamma}>0$ $(j=M, E, T) ;(2) \frac{\partial i^{i^{*}}}{\partial \gamma}>0, \frac{\partial i^{i^{*}}}{\partial \gamma}>0, \frac{\partial \pi_{M}^{*}}{\partial \gamma}>0, \frac{\partial \pi_{E}^{i^{*}}}{\partial \gamma}>0(i=M, E, T)$.

Proposition 13 indicates that the optimal product sales price, logistics service level, GAP comprehensive index level, the manufacturer's profit, and the e-commerce platform's profit all increase with the increase of logistics services utility elasticity coefficient in model M, model E, and model $\mathrm{T}$. The result is reasonable. This is because the increase of the logistics service utility elasticity coefficient is conducive to the e-commerce platform improving the product sales price and the level of logistics service and then increases the product market demand. The spillover effect will induce the collector to achieve a better GAP comprehensive index level, thereby enhancing channel profitability.

Proposition 14. The impact of the logistics service cost elasticity coefficient on the equilibrium strategies and profits of the manufacturer and the e-commerce platform is as follows: (1) $\frac{\partial A_{j}^{*}}{\partial \eta}<0$ $(j=M, E, T) ;(2) \frac{\partial p^{i^{*}}}{\partial \eta}<0, \frac{\partial s^{i^{*}}}{\partial \eta}<0, \frac{\partial \pi_{M}^{i *}}{\partial \eta}<0, \frac{\partial \pi_{E}^{i *}}{\partial \eta}<0(i=M, E, T)$.

Different from Proposition 13, In model M, model E, and model T, the optimal product sales price, logistics service level, GAP comprehensive index level, the manufacturer's profit, and the e-commerce platform's profit all decrease with the increase of the logistics services utility elasticity coefficient in model M, model E, and model T. Proposition 14 is the converse of Proposition 13. 


\section{Extension}

In this section, we will consider the impact of GAP effectiveness differences on the selection of recycling channels from the perspective of the manufacturer, the e-commerce platform, the consumer, and the ecological environment.

\subsection{The Perspective of the Manufacturer}

As a remanufacturer, the manufacturer has the option to collect used products or to outsource this activity to another agent, the e-commerce platform, or the third-party collector. From the perspective of the manufacturer, this means that the E-CLSC system takes the manufacturer's profit maximization as the goal when choosing the recycling channel and when making the optimal decisions. Through comparison, we achieve proposition 15.

Proposition 15. (1) If the third-party recycler is not considered to collect used products, when $h_{E}>h_{M} \sqrt{\frac{4 \theta \eta-\gamma^{2}}{G_{M}}-\frac{\left(4 \theta \eta-\gamma^{2}-2 G_{M}\right)}{G_{M}} \sqrt{\frac{2 \theta \eta}{2 \theta \eta-G_{M}}}}$, we have $\pi_{M}^{\mathrm{E}^{*}}>\pi_{M}^{\mathrm{M}^{*}}$; (2) If the ecommerce platform is not considered to collect used products, when $h_{T}>\sqrt{2} h_{M}$, we have $\pi_{M}^{\mathrm{T}^{*}}>\pi_{M}^{\mathrm{M}^{*}}$; (3) If the manufacturer is not considered to collect used products, and

$h_{T}>h_{E} \sqrt{1+\frac{2 \theta \eta}{G_{E}}-\frac{\left(G_{E}+\gamma^{2}\right)^{2}}{8 \theta \eta G_{E}}-\frac{\left(4 \theta \eta-\gamma^{2}-G_{E}\right) \sqrt{\left(4 \theta \eta-G_{E}\right)^{2}+\left(8 \theta \eta+\gamma^{2}+2 G_{E}\right) \gamma^{2}}}{8 \theta \eta G_{E}}}$ we have $\pi_{M}^{\mathrm{T}^{*}}>\pi_{M}^{\mathrm{E}^{*}}$.

Proposition 15 implies that the manufacturer should always collect to maximize their profits; however, the e-commerce platform or the third-party collector has a higher GAP effectiveness. In addition, through Figure 10, it is possible to show how the GAP effectiveness difference affects the recycling channel choice from the perspective of the manufacturer.

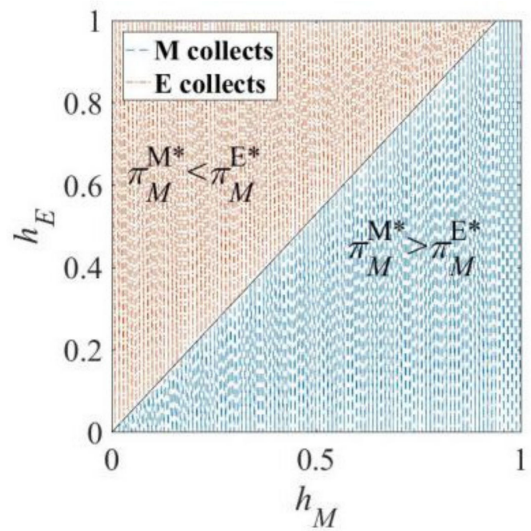

(a)

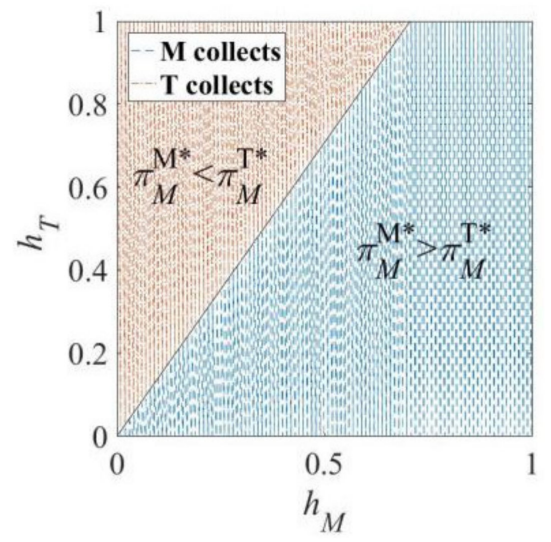

(b)

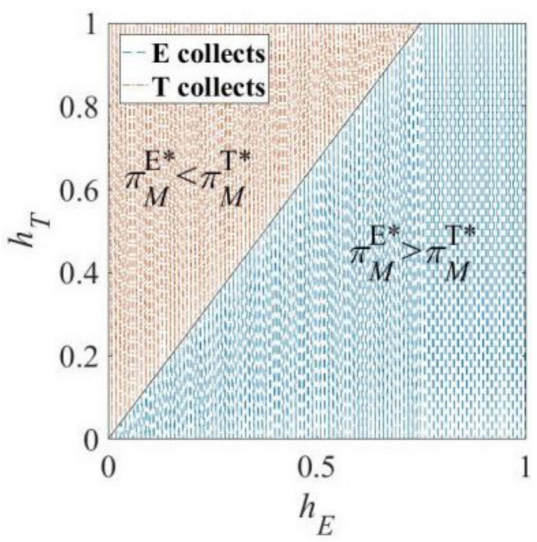

(c)

Figure 10. The choice of recycling channel from the perspective of the manufacturer.

From Figure 10a (The third-party recycler is not considered to collect used products) and Figure 10b (The e-commerce platform is not considered to collect used products), it can be seen that manufacturer recycling is the best if the manufacturer's GAP effectiveness is greater than a certain threshold. From Figure 10c (The manufacturer is not considered to collect used products), we can determine that if the manufacturer chooses to outsource the recycling activity, it is better to outsource the e-commerce platform when the GAP effectiveness of the e-commerce platform is greater than a certain threshold. 


\subsection{The Perspective of the E-Commerce Platform}

As a leader, whether the e-commerce platform prefers to conduct the recycling has a great impact on the manufacturer's decisions. From the perspective of the e-commerce platform, this means that the E-CLSC system takes the e-commerce platform's profit maximization as the goal when choosing the recycling channel and when making the optimal decisions. Through comparison, we achieve proposition 16.

Proposition 16. (1) If the third-party recycler is not considered for the collection of used products, when $h_{E}>\sqrt{2} h_{M}$, we have $\pi_{E}^{\mathrm{E}^{*}}>\pi_{E}^{\mathrm{M}^{*}} ;$ (2) If the e-commerce platform is not considered for the collection of used products, and $h_{T}>\sqrt{2} h_{M}$, we have $\pi_{E}^{\mathrm{T}^{*}}>\pi_{E}^{\mathrm{M}^{*}}$. (3) If the manufacturer is not considered for the collection of used products, and $h_{T}>h_{E}$, we have $\pi_{E}^{\mathrm{T}^{*}}>\pi_{E}^{\mathrm{E}^{*}}$.

Proposition 16 demonstrates that the e-commerce platform should always collect to maximize their profits; however, the manufacturer or the third-party collector has a higher GAP effectiveness. Next, using Figure 11, we intuitively show that how the GAP effectiveness difference affects the choice of the recycling channel from the perspective of the e-commerce platform.

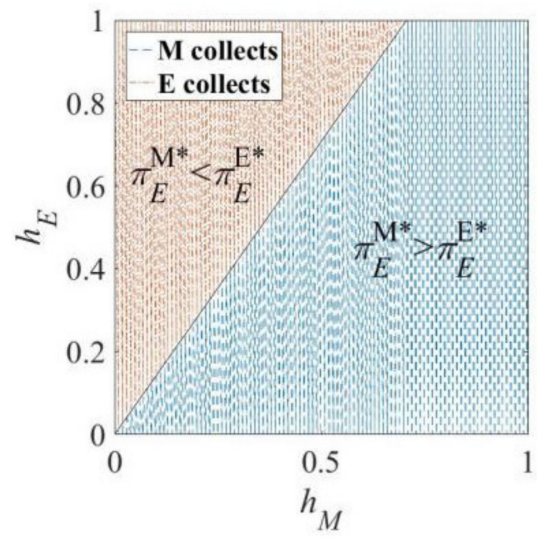

(a)



(b)

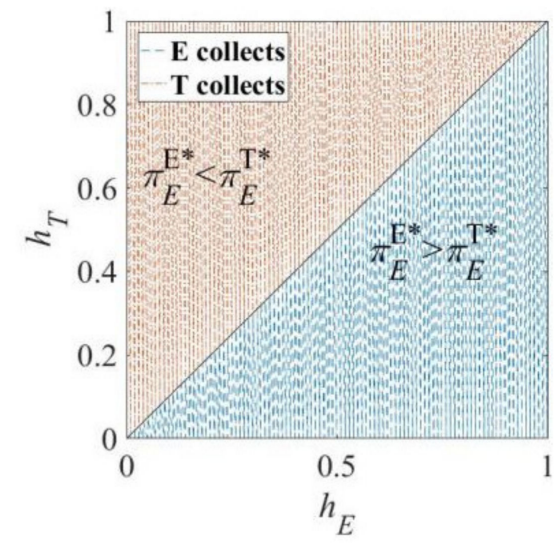

(c)

Figure 11. The choice of recycling channel from the perspective of the e-commerce platform.

Comparing Figure 11a (The third-party recycler is not considered to collect used products) and Figure 11b (The e-commerce platform is not considered to collect used products), we can see that manufacturer recycling is also the best if the manufacturer's GAP effectiveness is greater than a certain threshold. From Figure 11c (The manufacturer is not considered to collect used products), we can determine that if the manufacturer chooses to outsource the recycling activity, then the e-commerce platform also prefers a third-party recycler with higher GAP effectiveness. Otherwise, the e-commerce platform will actively choose to recycle by themselves.

\subsection{The Perspective of the Consumer}

Guide et al. [37] point out that the size of the market demand for a product is largely regarded as the degree of consumer product recognition. From the perspective of the consumer, this means that the E-CLSC system takes the product market demand maximization as the goal to choose the recycling channel and to make optimal decisions. Through comparison, we achieve proposition 17.

Proposition 17. (1) If the third-party recycler is not considered for the collection of used products when $h_{E}>\sqrt{2} h_{M}$, we have $q^{\mathrm{E}^{*}}>q^{\mathrm{M}^{*}} ;$; (2) if the e-commerce platform is not considered for the collection of used products, and $h_{T}>\sqrt{2} h_{M}$, we have $q^{T^{*}}>q^{\mathrm{M}^{*}}$. (3) If the manufacturer is not considered for the collection of used products, and $h_{T}>h_{E}$, we have $q^{T^{*}}>q^{E^{*}}$. 
Proposition 17 confirms an interesting finding. When the GAP effectiveness of the manufacturer is greater than a certain threshold, the e-commerce platform and consumer preferences for the recycling channel are consistent. More specifically, Figure 12 shows that how the GAP effectiveness difference affects the choice of the recycling channel from the perspective of the consumer.

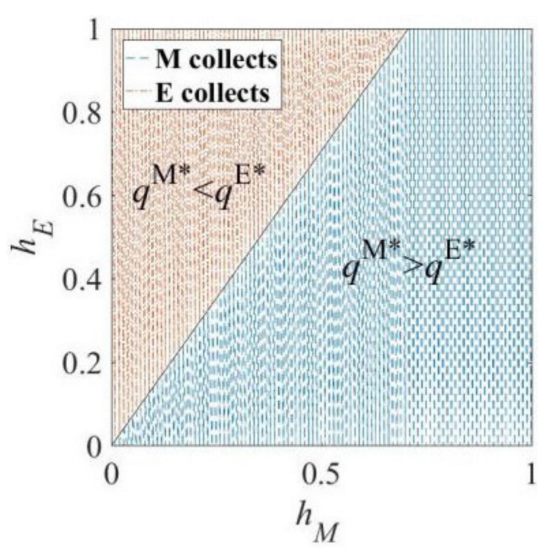

(a)

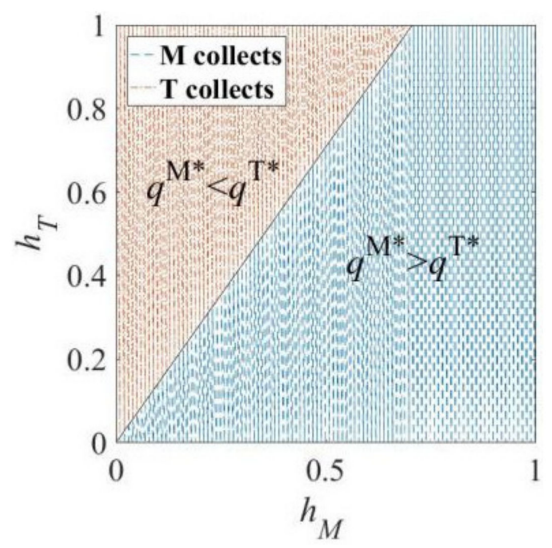

(b)

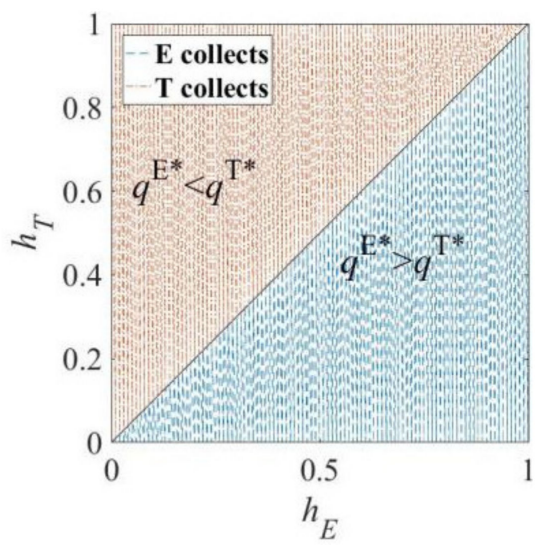

(c)

Figure 12. The choice of recycling channel from the perspective of the consumer.

Through Figure 12a (The third-party recycler is not considered to collect used products) and Figure 12b (The e-commerce platform is not considered to collect used products), we also found that manufacturer recycling is also the best if the manufacturer's GAP effectiveness is greater than a certain threshold from the perspective of the consumer. Figure 12c (The manufacturer is not considered to collect used products) shows that if the manufacturer chooses to outsource the recycling activity, the consumer also prefers the collector who has the higher GAP effectiveness.

\subsection{The Perspective of the Ecological Environment}

According to the study of Guide and Wassenhove [38], it can be assumed that the eco-environmental performance is measured by the recovery rate of used products in the E-CLSC recycling channel. From the perspective of the ecological environment, this means that the E-CLSC system takes the recovery rate of used products maximization as the goal when choosing the recycling channel and when making the optimal decisions. Through comparison, we achieve proposition 17.

Proposition 18. (1) If the third-party recycler is not considered in the collection of used product, when $h_{E}>h_{M} \sqrt{1+\frac{G_{M}}{4 \theta \eta-\gamma^{2}-G_{M}}}$, we have $\tau^{\mathrm{E}^{*}}>\tau^{\mathrm{M}^{*}}$; (2) if the e-commerce platform is not considered in the collection of used products, and $h_{T}>\sqrt{2} h_{M}$, we have $\tau^{\mathrm{T}^{*}}>\tau^{\mathrm{M}^{*}}$. (3) If the manufacturer is not considered in the collection of used products, and $h_{T}>h_{E} \sqrt{2-\frac{G_{E}}{4 \theta \eta-\gamma^{2}+G_{E}}}$, we have $\tau^{\mathrm{T}^{*}}>\tau^{\mathrm{E}^{*}}$.

From Proposition 18, we can determine that when the GAP effectiveness of the manufacturer is greater than a certain threshold, the manufacturer should always collect in order to maximize environmental performance. More specifically, Figure 13 shows the regions in the $h$-space where the manufacturer is better off outsourcing from the perspective of the ecological environment. 




(a)

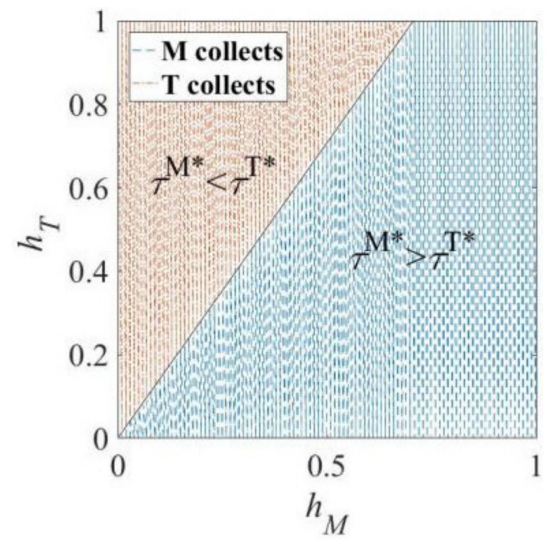

(b)

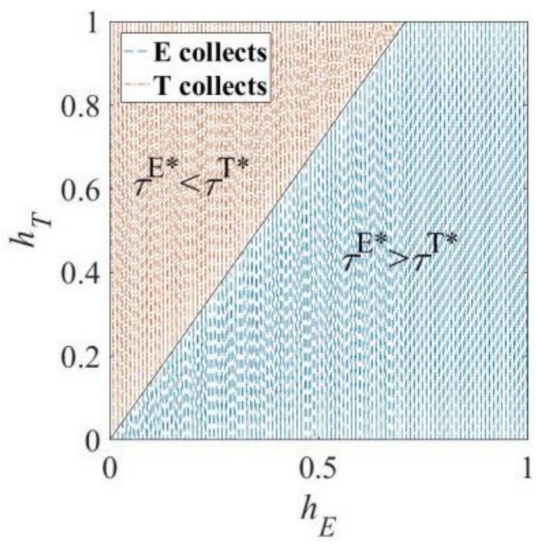

(c)

Figure 13. The choice of recycling channel from the perspective of the ecological environment.

Through Figure 13a (The third-party recycler is not considered to collect used products) and Figure 13b (The e-commerce platform is not considered to collect used products), we also found that manufacturer recycling is also the best if the manufacturer's GAP effectiveness is greater than a certain threshold from the perspective of the ecological environment. Figure 13c (The manufacturer is not considered to collect used products) shows that when the GAP effectiveness of the e-commerce platform is greater than a certain threshold, the e-commerce platform should always collect in order to maximize environmental performance.

\section{Conclusions and Future Research}

In recent years, more and more scholars and enterprises have paid attention to E-CLSC research. By analyzing the operation structure and interest relationship of E-CLSC, we established different decision models for recycling organizations, including the manufacturer with remanufacturing capability, the e-commerce platform, and the third-party recycler. Through the comparative analysis of E-CLSC equilibrium strategies and member profits, we also produced some interesting results, which can provide useful guidelines for the actual operation of enterprises.

First, the implementation of a remanufacturing strategy can not only effectively reduce product sales price, but it can also improve the product logistics service level. Moreover, it can also increase the profits of both the manufacturer and the e-commerce platform. Therefore, differences in terms of recycling organizers will also affect the equilibrium strategies of the manufacturer and the e-commerce platform. In reality, the manufacturer only considers outsourcing recycling when its GAP effectiveness is low.

Second, if the effectiveness of the GAP of recycling organizations is the same, the manufacturer's recycling is optimal in any perspective. On the other hand, if the GAP effectiveness of recycling organizations is different, the optimal recycling channel is significantly affected by the GAP effectiveness of recycling organizations. At the same time, from the perspective of the manufacturer and the e-commerce platform, there are conflict areas in the selection of recycling channels. However, the e-commerce platform and consumer preferences for the recycling channel are consistent. From the perspective of the manufacturer and the ecological environment, the recycling channel selection is only consistent when e-commerce platform recycling is not considered and when there are significant differences in other scenarios.

Finally, the logistics service level of the e-commerce platform, the level of GAP comprehensive index, and member profits are improved with the increase of the effectiveness of GAP of the recycling organizations. The increase of the utility elasticity coefficient of product logistics service level will lead to the increase of the product sale price, the GAP comprehensive index level, the product logistics service level, and the profits of the system 
members. On the contrary, the increase of the cost elasticity coefficient of the product logistics service level will lead to the decrease of product sale price, GAP comprehensive index level, product logistics service level, and the profits of the system members. Therefore, in reality, we should face up to the effective response of consumer investment activities. Recycling organizers can strengthen consumer interaction during the recycling process and $\mathrm{cab}$ provide high-quality recycling services. The government should strengthen the concept of green education and guide the consumer to participate in recycling waste products through publicity activities.

Although this paper draws some valuable and meaningful conclusions based on theoretical analysis, there are still many problems to be solved. For example, the choice of e-CLSC recycling channels and pricing service decisions can be further studied by combining the differential pricing or demand uncertainty scenarios of new products and remanufactured products.

Author Contributions: Conceptualization, K.L., C.L. and R.G.; methodology, K.L.; software, K.L.; formal analysis, K.L. and R.G.; writing—original draft preparation, K.L. and C.L.; writing—review and editing, R.G. and K.L. All authors have read and agreed to the published version of the manuscript.

Funding: This research is supported by the Tianjin Research Innovation Project for Postgraduate Students (Grant No.2019YJSB003) and the National Social Science Foundation of China (Grant No.18BJY009).

Acknowledgments: The authors are particularly grateful to the editors and reviewers for their most insightful and valuable comments on this paper, which played an important role in improving the quality of the research. We also gratefully acknowledge the support from the Tianjin Research Innovation Project for Postgraduate Students (Grant No.2019YJSB003) and the National Social Science Foundation of China (Grant No.18BJY009).

Conflicts of Interest: The authors declare no conflict of interest.

\section{Appendix A}

Proof of Lemma A1. In model N, we assume that the marginal profit of the product obtained by the e-commerce platform is $m^{\mathrm{N}}$, that is $m^{\mathrm{N}}=p^{\mathrm{N}}-w^{\mathrm{N}}$. Then, $p^{\mathrm{N}}=m^{\mathrm{N}}+w^{\mathrm{N}}$, which is substituted into Equation (2), and we obtained $\bar{\pi}_{M}^{\mathrm{N}}=\left(w^{\mathrm{N}}-c_{n}\right)\left(1-\frac{m^{\mathrm{N}}+w^{\mathrm{N}}-\gamma s^{\mathrm{N}}}{\theta}\right)$. Taking the second-order partial derivatives of $\bar{\pi}_{M}^{\mathrm{N}}$ with respect to $w^{\mathrm{N}}$, we have $\frac{\partial^{2} \bar{\pi}_{M}^{\mathrm{N}}}{\partial\left(w^{\mathrm{N}}\right)^{2}}=-\frac{2}{\theta}<0$

Proof of Proposition A1. According to Lemma 1, we obtain $w^{\mathrm{N}^{*}}\left(m^{\mathrm{N}},{ }^{\mathrm{N}}\right)=\frac{\theta+c_{n}-m^{\mathrm{N}}+\gamma s^{\mathrm{N}}}{2}$. Substituting it into Equation (3), we have $\bar{\pi}_{E}^{\mathrm{N}}=\frac{m^{\mathrm{N}}\left(\theta-c_{n}-m^{\mathrm{N}}+\gamma s^{\mathrm{N}}\right)}{2 \theta}-\frac{1}{2} \eta\left(s^{\mathrm{N}}\right)^{2}$. The Hessian matrix of $\bar{\pi}_{E}^{\mathrm{N}}$ is $H\left(m^{\mathrm{N}}, s^{\mathrm{N}}\right)=\left[\begin{array}{cc}-\frac{1}{\theta} & \frac{\gamma}{2 \theta} \\ \frac{\gamma}{2 \theta} & -\eta\end{array}\right]$. Obviously, $\frac{\partial^{2} \bar{\pi}_{E}^{\mathrm{N}}}{\partial\left(m^{\mathrm{N}}\right)^{2}}=-\frac{1}{\theta}<0$ because $\theta \eta-\gamma^{2}>0$, so $\left|H\left(m^{\mathrm{N}},{ }^{\mathrm{N}}\right)\right|=\frac{4 \theta \eta-\gamma^{2}}{4 \theta^{2}}>0$. Namely, the profit function $\bar{\pi}_{E}^{\mathrm{N}}$ is strictly concave in $m^{\mathrm{N}}$ and $s^{\mathrm{N}}$. Solving equations $\frac{\partial \bar{\pi}_{E}^{\mathrm{N}}}{\partial m^{\mathrm{N}}}=0$ and $\frac{\partial \bar{\pi}_{E}^{\mathrm{N}}}{\partial s^{\mathrm{N}}}=0$, we obtain $m^{\mathrm{N}^{*}}=\frac{2 \theta \eta\left(\theta-c_{n}\right)}{4 \theta \eta-\gamma^{2}}$ and $s^{\mathrm{N}^{*}}=\frac{\gamma\left(\theta-c_{n}\right)}{4 \theta \eta-\gamma^{2}}$. Substituting them into $w^{\mathrm{N}^{*}}\left(m^{\mathrm{N}}, s^{\mathrm{N}}\right)$, we obtain $w^{\mathrm{N}^{*}}=\frac{\theta^{2} \eta+3 \theta \eta c_{n}-\gamma^{2} c_{n}}{4 \theta \eta-\gamma^{2}}$. Then, we assert that $p^{\mathrm{N}^{*}}=m^{\mathrm{N}^{*}}+w^{\mathrm{N}^{*}}$. Substituting $p^{\mathrm{N}^{*}}$ and $s^{\mathrm{N}^{*}}$ into Equation (1), we achieve $q^{\mathrm{N}^{*}}$. 
Proof of Lemma A2. In the model M, we assume that the marginal profit of the product obtained by the e-commerce platform is $m^{\mathrm{M}}$, that is $p^{\mathrm{M}}=m^{\mathrm{M}}+w^{\mathrm{M}}$. Substituting it into Equation (4), we achieve $\bar{\pi}_{M}^{\mathrm{M}}=\left(\left(w^{\mathrm{M}}-c_{n}\right)+(\Delta-a) h_{M} A_{M}\right)\left(1-\frac{m^{\mathrm{M}}+w^{\mathrm{M}}-\gamma s^{\mathrm{M}}}{\theta}\right)-$ $\frac{1}{2}\left(A_{M}\right)^{2}$. The Hessian matrix of $\bar{\pi}_{M}^{\mathrm{M}}$ is $H\left(w^{\mathrm{M}}, A_{M}\right)=\left[\begin{array}{cc}-\frac{2}{\theta} & -\frac{h_{M}(\Delta-a)}{\theta} \\ -\frac{h_{M}(\Delta-a)}{\theta} & -1\end{array}\right]$ because $\theta>c_{n}>0$ and $c_{n}-h_{M}^{2}(\Delta-a)^{2}>0$, so $\frac{\partial^{2} \pi_{M}^{\mathrm{M}}}{\partial\left(w^{\mathrm{M}}\right)^{2}}=-\frac{2}{\theta}<0$ and $\left|H\left(w^{\mathrm{M}}, A_{M}\right)\right|=$ $\frac{2 \theta-h_{M}^{2}(\Delta-a)^{2}}{\theta^{2}}>0$.

Proof of Proposition A2. Based on Lemma 2, we assert that $w^{\mathrm{M}^{*}}\left(m^{\mathrm{M}}, \mathrm{s}^{\mathrm{M}}\right)=$ $\frac{\left(\theta-m^{\mathrm{M}}+\gamma s^{\mathrm{M}}\right)\left(\theta-h_{M}^{2}(\Delta-a)^{2}\right)+\theta c_{n}}{2 \theta-h_{M}^{2}(\Delta-a)^{2}}$ and $A_{M}^{*}\left(m^{\mathrm{M}},{ }^{\mathrm{M}}\right)=\frac{\left(\theta-m^{\mathrm{M}}+\gamma s^{\mathrm{M}}-c_{n}\right) h_{M}(\Delta-a)}{2 \theta-h_{M}^{2}(\Delta-a)^{2}}$. Substituting them into Equation (5), we achieve $\bar{\pi}_{E}^{\mathrm{M}}=m^{\mathrm{M}}\left(1-\frac{m^{\mathrm{M}}-\gamma s^{\mathrm{M}}}{\theta}-\frac{\left(\theta-m^{\mathrm{M}}+\gamma s^{\mathrm{M}}\right)\left(\theta-h_{M}^{2}(\Delta-a)^{2}\right)+\theta c_{n}}{\theta\left(2 \theta-h_{M}^{2}(\Delta-a)^{2}\right)}\right)-$ $\frac{1}{2} \eta\left(s^{\mathrm{M}}\right)^{2}$. The Hessian matrix of $\bar{\pi}_{E}^{\mathrm{M}}$ is $H\left(m^{\mathrm{M}}, s^{\mathrm{M}}\right)=\left[\begin{array}{cc}-\frac{2}{2 \theta-h_{M}^{2}(\Delta-a)^{2}} & \frac{\gamma}{2 \theta-h_{M}^{2}(\Delta-a)^{2}} \\ \frac{\gamma}{2 \theta-h_{M}^{2}(\Delta-a)^{2}} & -\eta\end{array}\right]$. Similar to Lemma 2, The profit function $\bar{\pi}_{E}^{\mathrm{M}}$ is strictly concave in $m^{\mathrm{M}}$ and $s^{\mathrm{M}}$. Solving equations $\frac{\partial \bar{\pi}_{E}^{\mathrm{M}}}{\partial m^{\mathrm{M}}}=0$ and $\frac{\partial \bar{\pi}_{E}^{\mathrm{M}}}{\partial s^{\mathrm{M}}}=0$, we can assert that $m^{\mathrm{M}^{*}}=\frac{\left(\theta-c_{n}\right)\left(2 \theta \eta-G_{M}\right)}{4 \theta \eta-\gamma^{2}-2 G_{M}}$ and $s^{\mathrm{M}^{*}}=\frac{\gamma\left(\theta-c_{n}\right)}{4 \theta \eta-\gamma^{2}-2 G_{M}}$. Substituting them into Equation $w^{\mathrm{M}^{*}}\left(m^{\mathrm{M}}, s^{\mathrm{M}}\right)$ and Equation $A_{M}^{*}\left(m^{\mathrm{M}}, s^{\mathrm{M}}\right)$, we have $w^{\mathrm{M}^{*}}$ and $A_{M}^{*}$. Then, we assert that $p^{\mathrm{M}^{*}}=m^{\mathrm{M}^{*}}+w^{\mathrm{M}^{*}}$. Substituting $p^{\mathrm{M}^{*}}$ and $s^{\mathrm{M}^{*}}$ into Equation (1), we have $q^{\mathrm{M}^{*}}$

Proof of Lemma A3. In model E, we assume that the marginal profit of the product obtained by the e-commerce platform is $m^{\mathrm{E}}$, that is $p^{\mathrm{E}}=m^{\mathrm{E}}+w^{\mathrm{E}}$. Substituting it into Equation (6), we achieve $\bar{\pi}_{M}^{\mathrm{E}}=\left(w^{\mathrm{E}}-c_{n}\right)\left(1-\frac{m^{\mathrm{E}}+w^{\mathrm{E}}-\gamma s^{\mathrm{E}}}{\theta}\right)$. Given the transferring price $b^{\mathrm{E}}$, we can simply assert that $\frac{\partial^{2} \bar{\pi}_{M}^{\mathrm{E}}}{\partial\left(w^{\mathrm{E}}\right)^{2}}=-\frac{2}{\theta}<0 . \square$

Proof of Proposition A3. Based on Lemma 3, for any given transfer price $b^{\mathrm{E}}$, we can assert that $w^{\mathrm{E}^{*}}\left(b^{\mathrm{E}}, m^{\mathrm{E}}, s^{\mathrm{E}}, A_{E}\right)=\frac{\theta+c_{n}-m^{\mathrm{E}}+\gamma s^{\mathrm{E}}-h_{E} A_{E}\left(\Delta-b^{\mathrm{E}}\right)}{2}$. Substituting it into Equation (7), we obtain $\bar{\pi}_{E}^{\mathrm{E}}=\frac{\left(m^{\mathrm{E}}+h_{E} A_{E}\left(b^{\mathrm{E}}-a\right)\right)^{2}\left(\theta-c_{n}-m^{\mathrm{E}}+\gamma s^{\mathrm{E}}+h_{E} A_{E}\left(\Delta-b^{\mathrm{E}}\right)\right)}{2 \theta}$ $-\frac{1}{2} \eta\left(s^{\mathrm{E}}\right)^{2}-\frac{1}{2}\left(A_{E}\right)^{2}$. The Hessian matrix of $\bar{\pi}_{E}^{\mathrm{E}}$ is $H\left(m^{\mathrm{E}}, s^{\mathrm{E}} A_{E}\right)=$ $\left[\begin{array}{ccc}-\frac{1}{\theta} & \frac{\gamma}{2 \theta} & \frac{h_{E}\left(\Delta+a-2 b^{\mathrm{E}}\right)}{2 \theta_{2}} \\ \frac{\gamma}{2 \theta} & -\eta & \frac{\gamma h_{E}\left(b^{\mathrm{E}}-a\right)}{2 \theta} \\ \frac{h_{E}\left(\Delta+a-2 b^{\mathrm{E}}\right)}{2 \theta} & \frac{\gamma h_{E}\left(b^{\mathrm{E}}-a\right)}{2 \theta} & -1\end{array}\right]$. Because $\theta>c_{n}>0, \theta \eta-\gamma^{2}>0$, and $c_{n}-h_{E}^{2}(\Delta-a)^{2}>0$, so $\theta-h_{E}^{2}(\Delta-a)^{2}>0$, we can assert that $\frac{\partial^{2} \bar{\pi}_{E}^{\mathrm{E}}}{\partial\left(m^{\mathrm{E}}\right)^{2}}=-\frac{1}{\theta}<0$, $\frac{\partial^{2} \bar{\pi}_{E}^{\mathrm{E}}}{\partial\left(m^{\mathrm{E}}\right)^{2}} \frac{\partial^{2} \bar{\pi}_{E}^{\mathrm{E}}}{\partial\left(s^{\mathrm{E}}\right)^{2}}-\frac{\partial^{2} \bar{\pi}_{E}^{\mathrm{E}}}{\partial m^{\mathrm{E}} \partial s^{\mathrm{E}}} \frac{\partial^{2} \bar{\pi}_{E}^{\mathrm{E}}}{\partial s^{\mathrm{E}} \partial m^{\mathrm{E}}}=\frac{4 \theta \eta-\gamma^{2}}{4 \theta^{2}}>0,\left|H\left(m^{\mathrm{E}}, s^{\mathrm{E}}, A_{E}\right)\right|=$ 
$-\frac{\theta\left(4 \theta \eta-\gamma^{2}\right)-\gamma^{2} h_{E}^{2}\left(\Delta-b^{\mathrm{E}}\right)\left(b^{\mathrm{E}}-a\right)-\theta \eta h_{E}^{2}\left(\Delta+a-2 b^{\mathrm{E}}\right)^{2}}{4 \theta^{3}}<0$. Thus, the profit function $\bar{\pi}_{E}^{\mathrm{E}}$ is strictly concave in $m^{\mathrm{E}}, s^{\mathrm{E}}$, and $A_{E}$. Solving equations $\frac{\partial \bar{\pi}_{E}^{\mathrm{E}}}{\partial m^{\mathrm{E}}}=0, \frac{\partial \bar{\pi}_{E}^{\mathrm{E}}}{\partial s^{\mathrm{E}}}=0$, and $\frac{\partial \bar{\pi}_{E}^{\mathrm{E}}}{\partial A_{E}}=0$, we can assert that the optimal decisions for the e-commerce platform are $m^{\mathrm{E}^{*}}=$ $\frac{\eta\left(2 \theta-h_{E}^{2}(\Delta-a)\left(b^{\mathrm{E}}-a\right)\right)\left(\theta-c_{n}\right)}{4 \theta \eta-\gamma^{2}-G_{E}},{ }^{E^{*}}=\frac{\gamma\left(\theta-c_{n}\right)}{4 \theta \eta-\gamma^{2}-G_{E}}$, and $A_{E}^{*}=\frac{\eta h_{E}(\Delta-a)\left(\theta-c_{n}\right)}{4 \theta \eta-\gamma^{2}-G_{E}}$. Substituting them into Equation $w^{\mathrm{E} *}\left(b^{\mathrm{E}}, m^{\mathrm{E}}, s^{\mathrm{E}}, A_{E}\right)$, we can easily obtain that the optimal decision for the manufacturer is $w^{\mathrm{E}^{*}}=\frac{\theta \eta\left(\theta-h_{E}^{2}(\Delta-a)\left(\Delta-b^{\mathrm{E}}\right)\right)+c_{n}\left(3 \theta \eta-\gamma^{2}-\eta h_{E}^{2}(\Delta-a)\left(b^{\mathrm{E}}-a\right)\right)}{4 \theta \eta-\gamma^{2}-G_{E}}$. Thus, the optimal sales price is $p^{\mathrm{E}^{*}}=m^{\mathrm{E}^{*}}+w^{\mathrm{E}^{*}}=\frac{\theta \eta\left(3 \theta-h_{E}^{2}(\Delta-a)^{2}\right)+c_{n}\left(\theta \eta-\gamma^{2}\right)}{4 \theta \eta-\gamma^{2}-G_{E}}$. Substituting $p^{\mathrm{E}^{*}}$ and $s^{\mathrm{E}^{*}}$ into Equation (1), we have $q^{\mathrm{E} *}$.

Proof of Lemma A4. In the model $\mathrm{T}$, it is obvious that $\frac{\partial^{2} \pi_{T}^{\mathrm{T}}}{\partial\left(A_{T}\right)^{2}}=-1<0$. Thus, the optimal decision of the third-party is $A_{T}^{*}\left(b^{\mathrm{T}}, p^{\mathrm{T}}, s^{\mathrm{T}}\right)=\frac{h_{T}\left(\theta-p^{\mathrm{T}}+\gamma s^{\mathrm{T}}\right)\left(b^{\mathrm{T}}-a\right)}{\theta}$. We assume that the marginal profit of the product obtained by the e-commerce platform is $m^{\mathrm{T}}$, that is $p^{\mathrm{T}}=m^{\mathrm{T}}+w^{\mathrm{T}}$. Substituting them into Equation (8), similar to Lemma 1, because $\theta-h_{T}^{2}(\Delta-a)^{2}>0$ and $(\Delta-a)^{2}>\left(\Delta-b^{T}\right)\left(b^{T}-a\right)$, it is obvious that $\theta-$ $h_{T}^{2}\left(\Delta-b^{\mathrm{T}}\right)\left(b^{\mathrm{T}}-a\right)>0$. We can assert that $\frac{\partial^{2} \bar{\pi}_{M 2}^{\mathrm{T}}}{\partial\left(w^{\mathrm{T}}\right)^{2}}=-\frac{2\left(\theta-h_{T}^{2}\left(\Delta-b^{\mathrm{T}}\right)\left(b^{\mathrm{T}}-a\right)\right)}{\theta^{2}}<0 . \square$

Proof of Proposition A4. Based on Lemma 4, for any given transfer price $b^{T}$, sales price $p^{T}$ and logistic service level $s^{\mathrm{T}}$, we obtain the optimal response decisions of the manufacturer and the third-party as $w^{\mathrm{T}^{*}}=\frac{\left(\theta-2 h_{T}^{2}\left(\Delta-b^{\mathrm{T}}\right)\left(b^{\mathrm{T}}-a\right)\right)\left(\theta_{2}-m^{\mathrm{T}}+\gamma s^{\mathrm{T}}\right)+\theta c_{n}}{2\left(\theta-h_{T}^{2}\left(\Delta-b^{\mathrm{T}}\right)\left(b^{\mathrm{T}}-a\right)\right)}$ and $A_{T}^{*}=\frac{h_{T}\left(\theta-p^{\mathrm{T}}+\gamma s^{\mathrm{T}}\right)\left(b^{\mathrm{T}}-a\right)}{\theta}$. Substituting them into Equation (9), we have $\bar{\pi}_{E}^{\mathrm{T}}=\frac{m^{\mathrm{T}}\left(\theta-m^{\mathrm{T}}+\gamma s^{\mathrm{T}}-c_{n}\right)}{2\left(\theta-h_{T}^{2}\left(\Delta-b^{\mathrm{T}}\right)\left(b^{\mathrm{T}}-a\right)\right)}-\frac{1}{2} \eta\left(s^{\mathrm{T}}\right)^{2}$. The Hessian matrix of $\bar{\pi}_{E}^{\mathrm{T}}$ is $H\left(m^{\mathrm{T}}, s^{\mathrm{T}}\right)=$ $\left[\begin{array}{cc}-\frac{1}{\theta-h_{T}^{2}\left(\Delta-b^{\mathrm{T}}\right)\left(b^{\mathrm{T}}-a\right)} & \frac{\gamma}{\gamma} \\ \frac{2 \theta-2 h_{T}^{2}\left(\Delta-b^{\mathrm{T}}\right)\left(b^{\mathrm{T}}-a\right)}{2 \theta-2 h_{T}^{2}\left(\Delta-b^{\mathrm{T}}\right)\left(b^{\mathrm{T}}-a\right)} & -\eta\end{array}\right]$. Similar to Proposition 3, it is obvious that $\frac{\partial^{2} \bar{\pi}_{E}^{\mathrm{T}}}{\partial\left(m^{\mathrm{T}}\right)^{2}}=-\frac{1}{\theta-h_{T}^{2}\left(\Delta-b^{\mathrm{T}}\right)\left(b^{\mathrm{T}}-a\right)}<0$ and $\left|H\left(m^{\mathrm{T}}, s^{\mathrm{T}}\right)\right|=$ $\frac{4 \eta\left(\theta-h_{T}^{2}\left(\Delta-b^{\mathrm{T}}\right)\left(b^{\mathrm{T}}-a\right)\right)-\gamma^{2}}{4\left(\theta-h_{T}^{2}\left(\Delta-b^{\mathrm{T}}\right)\left(b^{\mathrm{T}}-a\right)\right)^{2}} \geq \frac{4 \theta \eta-G_{T}-\gamma^{2}}{4\left(\theta-h_{T}^{2}\left(\Delta-b^{\mathrm{T}}\right)\left(b^{\mathrm{T}}-a\right)\right)^{2}}>0$. Thus, the profit function $\bar{\pi}_{E}^{\mathrm{T}}$ is strictly concave in $m^{\mathrm{T}}$ and $s^{\mathrm{T}}$. Solving equations $\frac{\partial \bar{\pi}_{E}^{\mathrm{T}}}{\partial m^{\mathrm{T}}}=0$ and $\frac{\partial \bar{\pi}_{E}^{\mathrm{T}}}{\partial s^{\mathrm{T}}}=0$, we can assert that the optimal decisions for the e-commerce platform are $m^{\mathrm{T} *}=\frac{2 \eta\left(\theta-c_{n}\right)\left(\theta-h_{T}^{2}\left(\Delta-b^{\mathrm{T}}\right)\left(b^{\mathrm{T}}-a\right)\right)}{4 \theta \eta-\gamma^{2}-4 \eta h_{T}^{2}\left(\Delta-b^{\mathrm{T}}\right)\left(b^{\mathrm{T}}-a\right)}$ and $s^{\mathrm{T}^{*}}=\frac{\gamma\left(\theta-c_{n}\right)}{4 \theta \eta-\gamma^{2}-4 \eta h_{T}^{2}\left(\Delta-b^{\mathrm{T}}\right)\left(b^{\mathrm{T}}-a\right)}$. Substituting them into Equation $w^{\mathrm{T}^{*}}\left(b^{\mathrm{T}}, m^{\mathrm{T}}, s^{\mathrm{T}}\right)$, we can easily obtain that the optimal decision for the manufacturer is $w^{T^{*}}$. Furthermore, we achieve $p^{T^{*}}$ and $A_{T}^{*}$. Substituting $p^{T^{*}}$ and $s^{T *}$ into Equation (1), we have $q^{T^{*}}$.

Proof of Proposition Observation A2. According to Proposition 4, we determine that the manufacturer's profit is $\pi_{M}^{\mathrm{T}^{*}}=\frac{\eta^{2}\left(\theta-c_{n}\right)^{2}\left(\theta-h_{T}^{2}\left(\Delta-b^{\mathrm{T}}\right)\left(b^{\mathrm{T}}-a\right)\right)}{\left(4 \theta \eta-\gamma^{2}-4 \eta h_{T}^{2}\left(\Delta-b^{\mathrm{T}}\right)\left(b^{\mathrm{T}}-a\right)\right)^{2}}$. Taking the first 
derivatives of $\bar{\pi}_{M}^{\mathrm{T}}$ with respect to $b^{\mathrm{T}}$, we have $\frac{\partial \pi_{M}^{\mathrm{T} *}}{\partial b^{\mathrm{T}}}=$ $\frac{4 \eta^{2} h_{T}^{2}\left(\theta-c_{n}\right)^{2}\left(4 \theta \eta+\gamma^{2}-4 \eta h_{T}^{2}\left(\Delta-b^{\mathrm{T}}\right)\left(b^{\mathrm{T}}-a\right)\right)\left(\Delta+a-2 b^{\mathrm{T}}\right)}{\left(4 \theta \eta-\gamma^{2}-4 \eta h_{T}^{2}\left(\Delta-b^{\mathrm{T}}\right)\left(b^{\mathrm{T}}-a\right)\right)^{3}} . \quad$ Obviously, when $b^{\mathrm{T}}>\frac{\Delta+a}{2}$, we have $\frac{\partial \pi_{M}^{\mathrm{T} *}}{\partial b^{\mathrm{T}}}<0$; when $b^{\mathrm{T}}<\frac{\Delta+a}{2}$, we have $\frac{\partial \pi_{M}^{\mathrm{T}^{*}}}{\partial b^{\mathrm{T}}}>0 . \square$

Proof of Proposition A5. Because $\Delta>a, \theta>c_{n}, \theta \eta>\gamma^{2}$, and $c_{n}-h_{j}^{2}(\Delta-a)^{2}>0$, $\theta \eta-G_{j}>0$. According to Proposition 2-Proposition 4, we can assert that $\frac{\partial A_{M}^{*}}{\partial h_{M}}=$ $\frac{\eta(\Delta-a)\left(\theta-c_{n}\right)\left(4 \theta \eta-\gamma^{2}+2 G_{M}\right)}{\left(4 \theta \eta-\gamma^{2}-2 G_{M}\right)^{2}}>0, \frac{\partial A_{E}^{*}}{\partial h_{E}}=\frac{\eta(\Delta-a)\left(\theta-c_{n}\right)\left(4 \theta \eta-\gamma^{2}+G_{M}\right)}{\left(4 \theta \eta-\gamma^{2}-G_{E}\right)^{2}}>0$, $\frac{\partial A_{T}^{*}}{\partial h_{T}}=\frac{\eta(\Delta-a)\left(\theta-c_{n}\right)\left(4 \theta \eta-\gamma^{2}+G_{T}\right)}{2\left(4 \theta \eta-\gamma^{2}-G_{T}\right)^{2}}>0$. If $h_{M}=h_{E}=h_{T}=h$, it obvious that $A_{M}^{*}-A_{E}^{*}=\frac{\eta h(\Delta-a)\left(\theta-c_{n}\right) G}{\left(4 \theta \eta-\gamma^{2}-2 G\right)\left(4 \theta \eta-\gamma^{2}-G\right)}>0, A_{E}^{*}-A_{T}^{*}=\frac{\eta h(\Delta-a)\left(\theta-c_{n}\right)}{2\left(4 \theta \eta-\gamma^{2}-G\right)}>0$. In conclusion, we have $A_{M}^{*}>A_{E}^{*}>A_{T}^{*}$.

Proof of Proposition A6. Because $\Delta>a, \theta>c_{n}, \theta \eta>\gamma^{2}$, and $c_{n}-h_{j}^{2}(\Delta-a)^{2}>0$, $\theta \eta-G_{j}>0(j=M, E, T)$. According to Proposition 1-Proposition 4, we derive the following results $\frac{\partial p^{\mathrm{M}^{*}}}{\partial h_{M}}=-\frac{4\left(\theta-c_{n}\right)\left(\theta \eta-\gamma^{2}\right) G_{M}}{h_{M}\left(4 \theta \eta-\gamma^{2}-2 G_{M}\right)^{2}}<0, \frac{\partial \mathrm{E}^{*}}{\partial h_{E}}=-\frac{2\left(\theta-c_{n}\right)\left(\theta \eta-\gamma^{2}\right) G_{E}}{h_{E}\left(4 \theta \eta-\gamma^{2}-G_{E}\right)^{2}}<0, \frac{\partial p^{T^{*}}}{\partial h_{T}}=$ $-\frac{2\left(\theta-c_{n}\right)\left(\theta \eta-\gamma^{2}\right) G_{T}}{h_{T}\left(4 \theta \eta-\gamma^{2}-G_{T}\right)^{2}}<0$. If $h_{M}=h_{E}=h_{T}=h$, it obvious that $p^{\mathrm{M}^{*}}-p^{\mathrm{E}^{*}}=$ $-\frac{\left(\theta-c_{n}\right)\left(\theta \eta-\gamma^{2}\right) G}{\left(4 \theta \eta-\gamma^{2}-2 G\right)\left(4 \theta \eta-\gamma^{2}-G\right)}<0, p^{E^{*}}-p^{T^{*}}=0$ and $p^{T^{*}}-p^{N^{*}}=-\frac{\left(\theta-c_{n}\right)\left(\theta \eta-\gamma^{2}\right) G}{\left(4 \theta \eta-\gamma^{2}-G\right)\left(4 \theta \eta-\gamma^{2}\right)}<0$. After the above analysis and discussion, it can be obtained that $p^{\mathrm{N}^{*}}>p^{\mathrm{T}^{*}}=p^{\mathrm{E}^{*}}>p^{\mathrm{M}^{*}}$.

Proof of Proposition A7. Because $\Delta>a, \theta>c_{n}, \theta \eta>\gamma^{2}$, and $c_{n}-h_{j}^{2}(\Delta-a)^{2}>0$, $\theta \eta-G_{j}>0(j=M, E, T)$. According to Proposition 1-Proposition 4, we can derive that $\frac{\partial s^{\mathrm{M} *}}{\partial h_{M}}=\frac{4 \gamma\left(\theta-c_{n}\right) G_{M}}{h_{M}\left(4 \theta \eta-\gamma^{2}-2 G_{M}\right)^{2}}>0, \frac{\partial s^{\mathrm{E} *}}{\partial h_{E}}=\frac{2 \gamma\left(\theta-c_{n}\right) G_{E}}{h_{E}\left(4 \theta \eta-\gamma^{2}-G_{E}\right)^{2}}>0, \frac{\partial s^{\top} *}{\partial h_{T}}=\frac{2 \gamma\left(\theta-c_{n}\right) G_{T}}{h_{T}\left(4 \theta \eta-\gamma^{2}-G_{T}\right)^{2}}>0$. If $h_{M}=h_{E}=h_{T}=h$, it obvious that $s^{\mathrm{M} *}-s^{\mathrm{E} *}=\frac{\gamma\left(\theta-c_{n}\right) G}{\left(4 \theta \eta-\gamma^{2}-2 G\right)\left(4 \theta \eta-\gamma^{2}-G\right)}>0, s^{\mathrm{E} *}-s^{\mathrm{T} *}=0$, $s^{\mathrm{T} *}-s^{\mathrm{N} *}=\frac{\gamma\left(\theta-c_{n}\right) G}{\left(4 \theta \eta-\gamma^{2}-G\right)\left(4 \theta \eta-\gamma^{2}\right)}>0$. In conclusion, we get $s^{\mathrm{M} *}>s^{\mathrm{E} *}=s^{\mathrm{T} *}>s^{\mathrm{N} *}$.

Proof of Proposition A8. Because $\Delta>a, \theta>c_{n}, \theta \eta>\gamma^{2}$, and $c_{n}-h_{j}^{2}(\Delta-a)^{2}>0$, $\theta \eta-G_{j}>0(j=M, E, T)$. According to Proposition 1-Proposition 4, we can derive that $\frac{\partial q^{\mathrm{M}^{*}}}{\partial h_{M}}=\frac{4 \eta\left(\theta-c_{n}\right) G_{M}}{h_{M}\left(4 \theta \eta-\gamma^{2}-2 G_{M}\right)^{2}}>0, \frac{\partial q^{\mathrm{E}^{*}}}{\partial h_{E}}=\frac{2 \eta\left(\theta-c_{n}\right) G_{E}}{h_{E}\left(4 \theta \eta-\gamma^{2}-G_{E}\right)^{2}}>0, \frac{\partial q^{\mathrm{T}^{*}}}{\partial h_{T}}=$ $\frac{2 \eta\left(\theta-c_{n}\right) G_{T}}{h_{T}\left(4 \theta \eta-\gamma^{2}-G_{T}\right)^{2}}>0$. If $h_{M}=h_{E}=h_{T}=h$, it obvious that $q^{\mathrm{M}^{*}}-q^{\mathrm{E} *}=$ $\frac{\eta\left(\theta-c_{n}\right) G}{\left(4 \theta \eta-\gamma^{2}-2 G\right)\left(4 \theta \eta-\gamma^{2}-G\right)}>0, q^{\mathrm{E}^{*}}-q^{\mathrm{T}^{*}}=0, q^{\mathrm{T}^{*}}-q^{\mathrm{N}^{*}}=\frac{\eta\left(\theta-c_{n}\right) G}{\left(4 \theta \eta-\gamma^{2}-G\right)\left(4 \theta \eta-\gamma^{2}\right)}>0$. From the above analysis and discussion, it can be concluded that $q^{\mathrm{M}^{*}}>q^{\mathrm{E} *}=q^{\mathrm{T}^{*}}>q^{\mathrm{N} *} \cdot \square$

Proof of Proposition A9. Because $\theta>c_{n}, \theta \eta>\gamma^{2}$, and $c_{n}-h_{j}^{2}(\Delta-a)^{2}>0, \theta \eta-G>0$. According to Proposition 1-Proposition 4, we can derive that $\frac{\partial \pi_{M}^{\mathrm{M}^{*}}}{\partial h_{M}}=$ $\frac{\eta\left(\theta-c_{n}\right)^{2}\left(4 \theta \eta+\gamma^{2}-2 G_{M}\right) G_{M}}{h_{M}\left(4 \theta \eta-\gamma^{2}-2 G_{M}\right)^{3}}>0, \frac{\partial \pi_{M}^{\mathrm{E}^{*}}}{\partial h_{E}}=\frac{4 \theta \eta^{2}\left(\theta-c_{n}\right)^{2} G_{E}}{h_{E}\left(4 \theta \eta-\gamma^{2}-G_{E}\right)^{3}}>0, \frac{\partial \pi_{M}^{\mathrm{T}^{*}}}{\partial h_{T}}=$ 
$\frac{\eta\left(\theta-c_{n}\right)^{2}\left(4 \theta \eta+\gamma^{2}-G_{T}\right) G_{T}}{2 h_{T}\left(4 \theta \eta-\gamma^{2}-G_{T}\right)^{3}}>0$. If $h_{M}=h_{E}=h_{T}=h$, we have $\pi_{M}^{\mathrm{M}^{*}}-\pi_{M}^{\mathrm{E}^{*}}=$ $\frac{\eta\left(\theta-c_{n}\right)^{2}\left(\gamma^{2}\left(4 \theta \eta-\gamma^{2}-2 G\right)+(2 \theta \eta-G) G\right) G}{2\left(4 \theta \eta-\gamma^{2}-2 G\right)\left(4 \theta \eta-\gamma^{2}-G\right)}>0, \pi_{M}^{\mathrm{E}^{*}}-\pi_{M}^{\mathrm{T}^{*}}=\frac{\eta\left(\theta-c_{n}\right)^{2} G}{4\left(4 \theta \eta-\gamma^{2}-G\right)^{2}}>0$, and $\pi_{M}^{\mathrm{T}^{*}}-\pi_{M}^{\mathrm{N}^{*}}=\frac{\eta\left(\theta-c_{n}\right)\left(4 \theta \eta(4 \theta \eta-G)-\gamma^{4}\right) G}{4\left(4 \theta \eta-\gamma^{2}\right)^{2}\left(4 \theta \eta-\gamma^{2}-G\right)^{2}}>0$. From the above analysis, we can determine that $\pi_{M}^{\mathrm{M}^{*}}>\pi_{M}^{\mathrm{E}^{*}}>\pi_{M}^{\mathrm{T}^{*}}>\pi_{M}^{\mathrm{N}^{*}} \cdot \square$

Proof of Proposition A10. Because $\theta>c_{n}, \theta \eta>\gamma^{2}$, and $c_{n}-h_{j}^{2}(\Delta-a)^{2}>0, \theta \eta-G>0$. According to Proposition 1-Proposition 4, we can derive the following results: $\frac{\partial \pi_{E}^{\mathrm{M}^{*}}}{\partial h_{M}}=\frac{2 \eta\left(\theta-c_{n}\right)^{2} G_{M}}{h_{M}\left(4 \theta \eta-\gamma^{2}-2 G_{M}\right)}>0, \frac{\partial \pi_{E}^{E^{*}}}{\partial h_{E}}=\frac{\eta\left(\theta-c_{n}\right)^{2} G_{E}}{h_{E}\left(4 \theta \eta-\gamma^{2}-G_{E}\right)}>0, \frac{\partial \pi_{E}^{\mathrm{T}^{*}}}{\partial h_{T}}=\frac{\eta\left(\theta-c_{n}\right)^{2} G_{T}}{h_{T}\left(4 \theta \eta-\gamma^{2}-G_{T}\right)}>0$. If $h_{M}=h_{E}=h_{T}=h$, we get $\pi_{E}^{\mathrm{M}^{*}}-\pi_{E}^{\mathrm{E}^{*}}=\frac{\eta\left(\theta-c_{n}\right)^{2} G}{2\left(4 \theta \eta-\gamma^{2}-2 G\right)\left(4 \theta \eta-\gamma^{2}-G\right)}>0$, $\pi_{E}^{\mathrm{E} *}-\pi_{E}^{\mathrm{T}^{*}}=0, \pi_{E}^{\mathrm{T}^{*}}-\pi_{E}^{\mathrm{N}^{*}}=\frac{\eta\left(\theta-c_{n}\right)^{2} G}{2\left(4 \theta \eta-\gamma^{2}\right)\left(4 \theta \eta-\gamma^{2}-G\right)}>0$. In conclusion, we know that $\pi_{E}^{\mathrm{M}^{*}}>\pi_{E}^{\mathrm{E}^{*}}=\pi_{E}^{\mathrm{T}^{*}}>\pi_{E}^{\mathrm{N}^{*}}$.

Proof of Proposition A11. Based on Proposition 9 and Proposition 10, we can determine that $\pi_{S C}^{\mathrm{M}^{*}}>\pi_{S C}^{\mathrm{E}^{*}}>\pi_{S C}^{\mathrm{N}^{*}}$ and $\pi_{S C}^{\mathrm{T}^{*}}-\pi_{S C}^{\mathrm{N}^{*}}>0$. Because $\pi_{S C}^{\mathrm{E}^{*}}-\pi_{S C}^{\mathrm{T}^{*}}=\frac{\eta\left(\theta-c_{n}\right)^{2} G}{8\left(4 \theta \eta-\gamma^{2}-G\right)^{2}}>0$, we have $\pi_{S C}^{\mathrm{M} *}>\pi_{S C}^{\mathrm{E}^{*}}>\pi_{S C}^{\mathrm{T}^{*}}>\pi_{S C}^{\mathrm{N}^{*}}$.

Proof of Proposition A12. The profit margin of the manufacturer and thee-commerce platform are $\delta_{M}^{\mathrm{N}^{*}}=\frac{\theta \eta\left(\theta-c_{n}\right)}{4 \theta \eta-\gamma^{2}}, \quad \delta_{M}^{\mathrm{M}^{*}}=\frac{\left(2 \theta \eta-G_{M}\right)\left(\theta-c_{n}\right)}{2\left(4 \theta \eta-\gamma^{2}-2 G_{M}\right)}, \delta_{M}^{\mathrm{E}^{*}}=\frac{\theta \eta\left(\theta-c_{n}\right)}{4 \theta \eta-\gamma^{2}-G_{E}}$, $\delta_{M}^{\mathrm{T}^{*}}=\frac{\left(4 \theta \eta-G_{T}\right)\left(\theta-c_{n}\right)}{4\left(4 \theta \eta-\gamma^{2}-G_{T}\right)}$, and $\delta_{E}^{\mathrm{N}^{*}}=\delta_{E}^{\mathrm{M}^{*}}=\delta_{E}^{\mathrm{E}^{*}}=\delta_{E}^{\mathrm{T}^{*}}=\frac{\theta-c_{n}}{2}$. We can easily assert that $\frac{\partial \delta_{M}^{\mathrm{M}^{*}}}{\partial h_{M}}=\frac{\gamma^{2}\left(\theta-c_{n}\right) G_{M}}{h_{M}\left(4 \theta \eta-\gamma^{2}-2 G_{M}\right)^{2}}>0, \frac{\partial \delta_{M}^{E^{*}}}{\partial h_{E}}=\frac{2 \theta \eta\left(\theta-c_{n}\right) G_{E}}{h_{E}\left(4 \theta \eta-\gamma^{2}-G_{E}\right)}>0, \frac{\partial \delta_{M}^{\mathrm{T} *}}{\partial h_{T}}=$ $\frac{\eta \gamma^{2}\left(\theta-c_{n}\right) G_{T}}{2 h_{T}\left(4 \theta \eta-\gamma^{2}-G_{T}\right)^{2}}>0, \frac{\partial \delta_{E}^{\mathrm{M}^{*}}}{\partial h_{M}}=\frac{\partial \delta_{E}^{E^{*}}}{\partial h_{E}}=\frac{\partial \delta_{E}^{\mathrm{T}^{*}}}{\partial h_{T}}=0$. If $h_{M}=h_{E}=h_{T}=h$, we have $\delta_{M}^{\mathrm{E}^{*}}-\delta_{M}^{\mathrm{M}^{*}}=\frac{\left(\theta-c_{n}\right)\left(2 \theta \eta-\gamma^{2}-G\right) G}{2\left(4 \theta \eta-\gamma^{2}-G\right)\left(4 \theta \eta-\gamma^{2}-2 G\right)}>0, \delta_{M}^{\mathrm{M}^{*}}-\delta_{M}^{\mathrm{T}^{*}}=\frac{\gamma^{2}\left(\theta-c_{n}\right) G}{4\left(4 \theta \eta-\gamma^{2}-G\right)\left(4 \theta \eta-\gamma^{2}-2 G\right)}>0$, $\delta_{M}^{\mathrm{T}^{*}}-\delta_{M}^{\mathrm{N}^{*}}=\frac{\gamma^{2}\left(\theta-c_{n}\right) G}{4\left(4 \theta \eta-\gamma^{2}-G\right)\left(4 \theta \eta-\gamma^{2}\right)}>0$. In conclusion, we can determine that $\delta_{M}^{\mathrm{E}^{*}}>\delta_{M}^{\mathrm{M}^{*}}>\delta_{M}^{\mathrm{T} *}>\delta_{M}^{\mathrm{N}^{*}}$

Proof of Corollary A1. Because $4 \theta \eta-\gamma^{2}-G_{E}>2 \theta \eta$, thus $\frac{\theta \eta\left(\theta-c_{n}\right)}{4 \theta \eta-\gamma^{2}-G_{E}}<\frac{\theta-c_{n}}{2}$. Based on Proposition 12, we conclude that $\delta_{E}^{i}>\delta_{M}^{i}(i=\mathrm{N}, \mathrm{M}, \mathrm{E}, \mathrm{T})$.

Proof of Proposition A13. Because $\theta>c_{n}, \theta \eta>\gamma^{2}$, and $c_{n}-h_{j}^{2}(\Delta-a)^{2}>0, \theta \eta-G_{j}>0$ $(j=M, E, T)$. According to Proposition 1-Proposition 4, we can derive the following results: $\frac{\partial w^{\mathrm{M}^{*}}}{\partial \gamma}=\frac{2 \gamma\left(\theta-c_{n}\right)\left(\theta \eta-G_{M}\right)}{\left(4 \theta \eta-\gamma^{2}-2 G_{M}\right)^{2}}>0, \frac{\partial w^{E^{*}}}{\partial \gamma}=\frac{2 \gamma \eta\left(\theta-c_{n}\right)\left(\theta-h_{E}^{2}\left(\Delta-b^{\mathrm{E}}\right)(\Delta-a)\right)}{\left(4 \theta \eta-\gamma^{2}-G_{E}\right)^{2}}>\frac{2 \gamma\left(\theta-c_{n}\right)\left(\theta \eta-G_{E}\right)}{\left(4 \theta \eta-\gamma^{2}-G_{E}\right)^{2}}>0$, $\frac{\partial w^{T^{*}}}{\partial \gamma}=\frac{\gamma\left(\theta-c_{n}\right)\left(2 \theta \eta-G_{T}\right)}{\left(4 \theta \eta-\gamma^{2}-2 G_{T}\right)^{2}}>0 ; \frac{\partial p^{\mathrm{M}^{*}}}{\partial \gamma}=\frac{2 \gamma\left(\theta-c_{n}\right)\left(3 \theta \eta-2 G_{M}\right)}{\left(4 \theta \eta-\gamma^{2}-2 G_{M}\right)^{2}}>0, \frac{\partial p^{*}}{\partial \gamma}=\frac{2 \gamma\left(\theta-c_{n}\right)\left(3 \theta \eta-G_{E}\right)}{\left(4 \theta \eta-\gamma^{2}-G_{E}\right)^{2}}>0$, $\frac{\partial p^{T^{*}}}{\partial \gamma}=\frac{2 \gamma\left(\theta-c_{n}\right)\left(3 \theta \eta-G_{T}\right)}{\left(4 \theta \eta-\gamma^{2}-G_{T}\right)^{2}}>0 ; \frac{\partial \mathrm{S}^{*}}{\partial \gamma}=\frac{\left(\theta-c_{n}\right)\left(4 \theta \eta+\gamma^{2}-2 G_{M}\right)}{\left(4 \theta \eta-\gamma^{2}-2 G_{M}\right)^{2}}>0, \frac{\partial \mathrm{S}^{*}}{\partial \gamma}=\frac{\left(\theta-c_{n}\right)\left(4 \theta \eta+\gamma^{2}-G_{E}\right)}{\left(4 \theta \eta-\gamma^{2}-G_{E}\right)^{2}}>0$, $\frac{\partial s^{*}}{\partial \gamma}=\frac{\left(\theta-c_{n}\right)\left(4 \theta \eta+\gamma^{2}-G_{T}\right)}{\left(4 \theta \eta-\gamma^{2}-G_{T}\right)^{2}}>0 ; \frac{\partial A_{M}^{*}}{\partial \gamma}=\frac{2 \gamma \eta h_{M}(\Delta-a)\left(\theta-c_{n}\right)}{\left(4 \theta \eta-\gamma^{2}-2 G_{M}\right)^{2}}>0, \frac{\partial A_{E}^{*}}{\partial \gamma}=\frac{2 \gamma \eta h_{E}(\Delta-a)\left(\theta-c_{n}\right)}{\left(4 \theta \eta-\gamma^{2}-G_{E}\right)^{2}}>0$, 


$$
\begin{aligned}
& \frac{\partial A_{T}^{*}}{\partial \gamma}=\frac{\gamma \eta h_{T}(\Delta-a)\left(\theta-c_{n}\right)}{\left(4 \theta \eta-\gamma^{2}-G_{T}\right)^{2}}>0 ; \frac{\partial q^{\mathrm{M} *}}{\partial \gamma}=\frac{2 \gamma \eta\left(\theta-c_{n}\right)}{\left(4 \theta \eta-\gamma^{2}-2 G_{M}\right)^{2}}>0, \frac{\partial q^{\mathrm{E}^{*}}}{\partial \gamma}=\frac{2 \gamma \eta\left(\theta-c_{n}\right)}{\left(4 \theta \eta-\gamma^{2}-G_{E}\right)^{2}}>0, \\
& \frac{\partial q^{\mathrm{T} *}}{\partial \gamma}=\frac{2 \gamma \eta\left(\theta-c_{n}\right)}{\left(4 \theta \eta-\gamma^{2}-G_{T}\right)^{2}}>0 ; \frac{\partial \pi_{M}^{\mathrm{M} *}}{\partial \gamma}=\frac{2 \gamma \eta\left(\theta-c_{n}\right)^{2}\left(2 \theta \eta-G_{M}\right)}{\left(4 \theta \eta-\gamma^{2}-2 G_{M}\right)^{3}}>0, \frac{\partial \pi_{M}^{\mathrm{E} *}}{\partial \gamma}=\frac{4 \gamma \theta \eta^{2}\left(\theta-c_{n}\right)^{2}}{\left(4 \theta \eta-\gamma^{2}-G_{E}\right)^{3}}>0, \\
& \frac{\partial \pi_{M}^{\mathrm{T} *}}{\partial \gamma}=\frac{\gamma \eta\left(\theta-c_{n}\right)^{2}\left(4 \theta \eta-G_{T}\right)}{\left(4 \theta \eta-\gamma^{2}-G_{T}\right)^{3}}>0 ; \frac{\partial \pi_{E}^{\mathrm{M}^{*}}}{\partial \gamma}=\frac{\gamma \eta\left(\theta-c_{n}\right)^{2}}{\left(4 \theta \eta-\gamma^{2}-2 G_{M}\right)^{2}}>0, \frac{\partial \pi_{E}^{\mathrm{E}^{*}}}{\partial \gamma}=\frac{\gamma \eta\left(\theta-c_{n}\right)^{2}}{\left(4 \theta \eta-\gamma^{2}-G_{E}\right)^{2}}>0, \\
& \frac{\partial \pi_{E}^{\mathrm{T}^{*}}}{\partial \gamma}=\frac{\gamma \eta\left(\theta-c_{n}\right)^{2}}{\left(4 \theta \eta-\gamma^{2}-G_{T}\right)^{2}}>0 .
\end{aligned}
$$

Proof of Proposition A14. Because $\theta>c_{n}, \theta \eta>\gamma^{2}$, and $c_{n}-h_{j}^{2}(\Delta-a)^{2}>0, \theta \eta-G_{j}>0$ $(j=M, E, T)$. According to Proposition 1- Proposition 4, we can derive the following results: $\frac{\partial w^{\mathrm{M}^{*}}}{\partial \eta}=-\frac{\gamma^{2}\left(\theta-c_{n}\right)\left(\theta \eta-G_{M}\right)}{\eta\left(4 \theta \eta-\gamma^{2}-2 G_{M}\right)^{2}}<0, \frac{\partial w^{\mathrm{E} *}}{\partial \eta}=-\frac{\gamma^{2}\left(\theta-c_{n}\right)\left(\theta-h_{E}^{2}\left(\Delta-b^{\mathrm{E}}\right)(\Delta-a)\right)}{\left(4 \theta \eta-\gamma^{2}-G_{E}\right)^{2}}<-\frac{2 \gamma\left(\theta-c_{n}\right)\left(\theta \eta-G_{E}\right)}{\eta\left(4 \theta \eta-\gamma^{2}-G_{E}\right)^{2}}<0$, $\frac{\partial w^{T^{*}}}{\partial \eta}=-\frac{\gamma^{2}\left(\theta-c_{n}\right)\left(2 \theta \eta-G_{T}\right)}{\left(4 \theta \eta-\gamma^{2}-2 G_{T}\right)^{2}}<0 ; \frac{\partial p^{\mathrm{M}^{*}}}{\partial \eta}=-\frac{\gamma^{2}\left(\theta-c_{n}\right)\left(3 \theta-2 G_{M}\right)}{\eta\left(4 \theta \eta-\gamma^{2}-2 G_{M}\right)^{2}}<0, \frac{\partial \mathrm{E}^{E^{*}}}{\partial \eta}=-\frac{\gamma^{2}\left(\theta-c_{n}\right)\left(3 \theta \eta-G_{E}\right)}{\eta\left(4 \theta \eta-\gamma^{2}-G_{E}\right)^{2}}<0$, $\frac{\partial p^{T^{*}}}{\partial \eta}=-\frac{\gamma^{2}\left(\theta-c_{n}\right)\left(3 \theta \eta-G_{T}\right)}{\eta\left(4 \theta \eta-\gamma^{2}-G_{T}\right)^{2}}<0 ; \frac{\partial s^{\mathrm{M}^{*}}}{\partial \eta}=-\frac{2 \gamma\left(\theta-c_{n}\right)\left(2 \theta \eta-G_{M}\right)}{\eta\left(4 \theta \eta-\gamma^{2}-2 G_{M}\right)^{2}}<0, \frac{\partial \mathrm{s}^{*}}{\partial \eta}=-\frac{\gamma\left(\theta-c_{n}\right)\left(4 \theta \eta-G_{E}\right)}{\eta\left(4 \theta \eta-\gamma^{2}-G_{E}\right)^{2}}<0$, $\frac{\partial s^{T^{*}}}{\partial \eta}=-\frac{\gamma\left(\theta-c_{n}\right)\left(4 \theta \eta-G_{T}\right)}{\eta\left(4 \theta \eta-\gamma^{2}-G_{T}\right)^{2}}<0 ; \frac{\partial A_{M}^{*}}{\partial \eta}=-\frac{\gamma^{2} h_{M}(\Delta-a)\left(\theta-c_{n}\right)}{\left(4 \theta \eta-\gamma^{2}-2 G_{M}\right)^{2}}<0, \frac{\partial A_{E}^{*}}{\partial \eta}=-\frac{\gamma^{2} h_{E}(\Delta-a)\left(\theta-c_{n}\right)}{\left(4 \theta \eta-\gamma^{2}-G_{E}\right)^{2}}<0$, $\frac{\partial A_{T}^{*}}{\partial \eta}=-\frac{\gamma^{2} h_{T}(\Delta-a)\left(\theta-c_{n}\right)}{2\left(4 \theta \eta-\gamma^{2}-G_{T}\right)^{2}}<0 ; \frac{\partial q^{\mathrm{M}^{*}}}{\partial \eta}=-\frac{\gamma^{2}\left(\theta-c_{n}\right)}{\left(4 \theta \eta-\gamma^{2}-2 G_{M}\right)^{2}}<0, \frac{\partial q^{\mathrm{E}^{*}}}{\partial \gamma}=-\frac{\gamma^{2}\left(\theta-c_{n}\right)}{\left(4 \theta \eta-\gamma^{2}-G_{E}\right)^{2}}<0$, $\frac{\partial q^{\mathrm{T}^{*}}}{\partial \eta}=-\frac{\gamma^{2}\left(\theta-c_{n}\right)}{\left(4 \theta \eta-\gamma^{2}-G_{T}\right)^{2}}<0 ; \frac{\partial \pi_{M}^{\mathrm{M}^{*}}}{\partial \eta}=-\frac{\gamma^{2}\left(\theta-c_{n}\right)^{2}\left(2 \theta \eta-G_{M}\right)}{\left(4 \theta \eta-\gamma^{2}-2 G_{M}\right)^{3}}<0, \frac{\partial \pi_{M}^{\mathrm{E}^{*}}}{\partial \eta}=-\frac{2 \gamma^{2} \theta \eta\left(\theta-c_{n}\right)^{2}}{\left(4 \theta \eta-\gamma^{2}-G_{E}\right)^{3}}<0$, $\frac{\partial \pi_{M}^{\mathrm{T}^{*}}}{\partial \eta}=-\frac{\gamma^{2}\left(\theta-c_{n}\right)^{2}\left(4 \theta \eta-G_{T}\right)}{2\left(4 \theta \eta-\gamma^{2}-G_{T}\right)^{3}}<0 ; \frac{\partial \pi_{E}^{\mathrm{M}^{*}}}{\partial \eta}=-\frac{\gamma^{2}\left(\theta-c_{n}\right)^{2}}{2\left(4 \theta \eta-\gamma^{2}-2 G_{M}\right)^{3}}<0, \frac{\partial \pi_{E}^{\mathrm{E}^{*}}}{\partial \eta}=-\frac{\gamma^{2}\left(\theta-c_{n}\right)^{2}}{2\left(4 \theta \eta-\gamma^{2}-G_{E}\right)^{2}}<0$, $\frac{\partial \pi_{E}^{T^{*}}}{\partial \eta}=-\frac{\gamma^{2}\left(\theta-c_{n}\right)^{2}}{2\left(4 \theta \eta-\gamma^{2}-G_{T}\right)^{2}}<0 . \square$

Proof of Proposition A15. We assume that $\frac{h_{E}}{h_{M}}=\lambda, \frac{h_{T}}{h_{M}}=\mu, \frac{h_{T}}{h_{E}}=\varphi$, thus $\lambda^{2} \in\left[0, \frac{1}{h_{M}^{2}}\right]$, $\mu^{2} \in\left[0, \frac{1}{h_{M}^{2}}\right], \varphi^{2} \in\left[0, \frac{1}{h_{E}^{2}}\right]$ because $\theta>c_{n}, \theta \eta>\gamma^{2}$, and $c_{n}-h_{j}^{2}(\Delta-a)^{2}>0$ $(j=M, E, T)$. (1) Based on Proposition 2 and Proposition 3, we can derive that $\pi_{M}^{\mathrm{M}^{*}}-\pi_{M}^{\mathrm{E}^{*}}=$ $\frac{\eta\left(\theta-c_{n}\right)^{2} G_{M} X_{1}(\lambda)}{2\left(4 \theta \eta-\gamma^{2}-2 G_{M}\right)^{2}\left(4 \theta \eta-\gamma^{2}-G_{E}\right)^{2}}$, where $X_{1}(\lambda)=\left(2 \theta \eta-G_{M}\right) G_{M} \lambda^{4}-2\left(4 \theta \eta-\gamma^{2}\right)\left(2 \theta \eta-G_{M}\right) \lambda^{2}$ $+8 \theta \eta\left(2 \theta \eta-G_{M}\right)-\gamma^{4}$. Let $\Omega=\lambda^{2} \leq \frac{1}{h_{M}^{2}}$, then $X_{1}(\Omega)=\left(2 \theta \eta-G_{M}\right) G_{M} \Omega^{2}-$ $2\left(4 \theta \eta-\gamma^{2}\right)\left(2 \theta \eta-G_{M}\right) \Omega+8 \theta \eta\left(2 \theta \eta-G_{M}\right)-\gamma^{4}$. From the properties of quadratic function, it is easy to conclude that there exists a unique optimal solution $\Omega_{1}^{*}=\frac{4 \theta \eta-\gamma^{2}}{G_{M}}-$

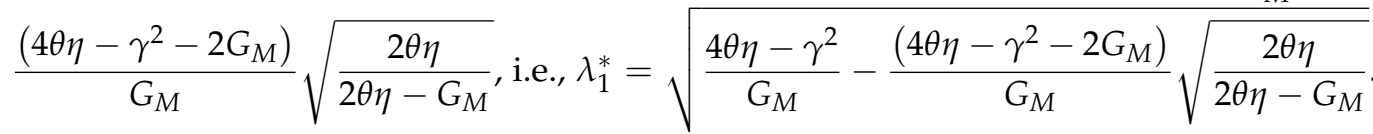
Additionally, because $\left(2 \theta \eta-G_{M}\right) G_{M}>0$, when $\lambda>\lambda_{1}^{*}$, we have $\pi_{M}^{\mathrm{E}^{*}}>\pi_{M}^{\mathrm{M}^{*}}$ or $\pi_{M}^{\mathrm{E}^{*}}<\pi_{M}^{\mathrm{M} *}$.

(2) Based on Proposition 2 and Proposition 4, we can easily assert that $\pi_{M}^{\mathrm{M} *}-\pi_{M}^{\mathrm{T} *}=$ $\frac{\eta\left(\theta-c_{n}\right)^{2}\left(2-\mu^{2}\right)\left(2\left(2 \theta \eta-G_{M}\right)\left(4 \theta \eta-G_{T}\right)-\gamma^{4}\right) G_{M}}{4\left(4 \theta \eta-\gamma^{2}-G_{T}\right)^{2}\left(4 \theta \eta-\gamma^{2}-2 G_{M}\right)}$. Because $2\left(2 \theta \eta-G_{M}\right)\left(4 \theta \eta-G_{T}\right)$ $-\gamma^{4}>0$, when $\mu>\sqrt{2}$, we have $\pi_{M}^{\mathrm{T} *}>\pi_{M}^{\mathrm{M} *}$ or $\pi_{M}^{\mathrm{T} *}<\pi_{M}^{\mathrm{M} *}$.

(3) Based on Proposition 3 and Proposition 4, we can easily assert that $\pi_{M}^{\mathrm{E} *}-\pi_{M}^{\mathrm{T} *}=$ $\frac{\eta\left(\theta-c_{n}\right)^{2} G_{M} Z_{1}(\varphi)}{4\left(4 \theta \eta-\gamma^{2}-G_{E}\right)\left(4 \theta \eta-\gamma^{2}-G_{T}\right)^{2}}$, where $Z_{1}(\varphi)=4 \theta \eta\left(8 \theta \eta-2 \gamma^{2}-G_{E}\right)+\left(\left(G_{E}+\gamma^{2}\right)^{2}\right.$ $\left.-8 \theta \eta\left(2 \theta \eta+G_{E}\right)\right) \varphi^{2}+4 \theta \eta G_{E} \varphi^{4}$. Let $\Psi=\varphi^{2} \leq \frac{1}{h_{E}^{2}}$, then $Z_{1}(\Psi)=4 \theta \eta\left(8 \theta \eta-2 \gamma^{2}-G_{E}\right)+$ $\left(\left(G_{E}+\gamma^{2}\right)^{2}-8 \theta \eta\left(2 \theta \eta+G_{E}\right)\right) \Psi+4 \theta \eta G_{E} \Psi^{2}$. From the properties of the quadratic function, it is easy to conclude that a unique optimal solution exists: $\Psi_{1}^{*}=1-$ 


$$
\frac{\frac{\left(4 \theta \eta-\gamma^{2}-G_{E}\right) \sqrt{\left(4 \theta \eta-G_{E}\right)^{2}+\left(8 \theta \eta+\gamma^{2}+2 G_{E}\right) \gamma^{2}}}{8 \theta \eta G_{E}}+\frac{2 \theta \eta}{G_{E}}-\frac{\left(G_{E}+\gamma^{2}\right)^{2}}{8 \theta \eta G_{E}} \text {, i.e., }}{\sqrt{1-\frac{\left(4 \theta \eta-\gamma^{2}-G_{E}\right) \sqrt{\left(4 \theta \eta-G_{E}\right)^{2}+\left(8 \theta \eta+\gamma^{2}+2 G_{E}\right) \gamma^{2}}}{8 \theta \eta G_{E}}}+\frac{2 \theta \eta}{G_{E}}-\frac{\left(G_{E}+\gamma^{2}\right)^{2}}{8 \theta \eta G_{E}}} \text {. Addi- }
$$

tionally, because $4 \theta \eta G_{E}>0$, when $\varphi>\varphi_{1}^{*}$, we have $\pi_{M}^{\mathrm{T}^{*}}>\pi_{M}^{\mathrm{E}^{*}}$, else $\pi_{M}^{\mathrm{T} *}<\pi_{M}^{\mathrm{E}^{*}} . \square$

Proof of Proposition A16. We assume that $\frac{h_{E}}{h_{M}}=\lambda, \frac{h_{T}}{h_{M}}=\mu, \frac{h_{T}}{h_{E}}=\varphi$, thus $\lambda^{2} \in\left[0, \frac{1}{h_{M}^{2}}\right]$, $\mu^{2} \in\left[0, \frac{1}{h_{M}^{2}}\right], \varphi^{2} \in\left[0, \frac{1}{h_{E}^{2}}\right]$ because $\theta>c_{n}, \theta \eta>\gamma^{2}$ and $c_{n}-h_{j}^{2}(\Delta-a)^{2}>0(j=M, E, T)$.

(1) Based on Proposition 2 and Proposition 3, we can derive that $\pi_{E}^{\mathrm{M}^{*}}-\pi_{E}^{\mathrm{E}^{*}}=$ $\frac{\eta\left(\theta-c_{n}\right)^{2} G_{M}\left(2-\lambda^{2}\right)}{2\left(4 \theta \eta-\gamma^{2}-2 G_{M}\right)\left(4 \theta \eta-\gamma^{2}-G_{E}\right)}$. It is obvious that when $\lambda>\sqrt{2}$, we have $\pi_{E}^{\mathrm{M}^{*}}<\pi_{E}^{\mathrm{E}^{*}}$ or $\pi_{E}^{\mathrm{M}^{*}}>\pi_{E}^{\mathrm{E}^{*}}$.

(2) Based on Proposition 2 and Proposition 4, we can derive that $\pi_{E}^{\mathrm{M}^{*}}-\pi_{E}^{\mathrm{T}^{*}}=$ $\frac{\eta\left(\theta-c_{n}\right)^{2} G_{M}\left(2-\mu^{2}\right)}{2\left(4 \theta \eta-\gamma^{2}-2 G_{M}\right)\left(4 \theta \eta-\gamma^{2}-G_{T}\right)}$. Because $4 \theta \eta-\gamma^{2}-2 G_{M}>0$ and $4 \theta \eta-\gamma^{2}-G_{T}>0$, thus, when $\mu>\sqrt{2}$, we have $\pi_{E}^{\mathrm{M}^{*}}<\pi_{E}^{\mathrm{T}^{*}}$, else $\pi_{E}^{\mathrm{M}^{*}}>\pi_{E}^{\mathrm{T}^{*}}$.

(3) Based on Proposition 3 and Proposition 4, we can derive that $\pi_{E}^{\mathrm{E}^{*}}-\pi_{E}^{\mathrm{T}^{*}}=$ $\frac{\eta\left(\theta-c_{n}\right)^{2} G_{E}\left(1-\varphi^{2}\right)}{2\left(4 \theta \eta-\gamma^{2}-G_{E}\right)\left(4 \theta \eta-\gamma^{2}-G_{T}\right)}$. Because $4 \theta \eta-\gamma^{2}-G_{E}>0$ and $4 \theta \eta-\gamma^{2}-G_{T}>0$, thus, when $\varphi>1$, we have $\pi_{E}^{\mathrm{E}^{*}}<\pi_{E}^{\mathrm{T}^{*}}$, else $\pi_{E}^{\mathrm{E}^{*}}>\pi_{E}^{\mathrm{T}^{*}}$

Proof of Proposition A17. We assume that $\frac{h_{E}}{h_{M}}=\lambda, \frac{h_{T}}{h_{M}}=\mu, \frac{h_{T}}{h_{E}}=\varphi$, thus $\lambda^{2} \in\left[0, \frac{1}{h_{M}^{2}}\right]$, $\mu^{2} \in\left[0, \frac{1}{h_{M}^{2}}\right], \varphi^{2} \in\left[0, \frac{1}{h_{E}^{2}}\right]$ because $\theta>c_{n}, \theta \eta>\gamma^{2}$, and $c_{n}-h_{j}^{2}(\Delta-a)^{2}>0$ $(j=M, E, T)$. (1) Based on Proposition 2 and Proposition 3, we can derive that $q^{\mathrm{M}^{*}}-q^{\mathrm{E}^{*}}=$ $\frac{\eta\left(\theta-c_{n}\right) G_{M}\left(2-\lambda^{2}\right)}{\left(4 \theta \eta-\gamma^{2}-2 G_{M}\right)\left(4 \theta \eta-\gamma^{2}-G_{E}\right)}$. It is obvious that when $\lambda>\sqrt{2}$, we have $q^{\mathrm{M}^{*}}<q^{\mathrm{E}^{*}}$, else $q^{\mathrm{M}^{*}}>q^{\mathrm{E}^{*}}$.

(2) Based on Proposition 2 and Proposition 4, we can derive that $q^{\mathrm{M}^{*}}-q^{\mathrm{T}^{*}}=$ $\frac{\eta\left(\theta-c_{n}\right) G_{M}\left(2-\mu^{2}\right)}{\left(4 \theta \eta-\gamma^{2}-2 G_{M}\right)\left(4 \theta \eta-\gamma^{2}-G_{T}\right)}$. Because $4 \theta \eta-\gamma^{2}-2 G_{M}>0$ and $4 \theta \eta-\gamma^{2}-G_{T}>0$, when $\mu>\sqrt{2}$, we have $q^{\mathrm{M}^{*}}<q^{\mathrm{T}^{*}}$ or $q^{\mathrm{M}^{*}}>q^{\mathrm{T}^{*}}$.

(3) Based on Proposition 3 and Proposition 4, we can derive that $q^{E^{*}}-q^{T^{*}}=$ $\frac{\eta\left(\theta-c_{n}\right) G_{E}\left(1-\varphi^{2}\right)}{\left(4 \theta \eta-\gamma^{2}-G_{E}\right)\left(4 \theta \eta-\gamma^{2}-G_{T}\right)}$. Because $4 \theta \eta-\gamma^{2}-G_{E}>0$ and $4 \theta \eta-\gamma^{2}-G_{T}>0$, when $\varphi>1$, we have $q^{\mathrm{E}^{*}}<q^{\mathrm{T}^{*}}$, else $q^{\mathrm{E}^{*}}>q^{\mathrm{T}^{*}} . \square$

Proof of Proposition A18. We assume that $\frac{h_{E}}{h_{M}}=\lambda, \frac{h_{T}}{h_{M}}=\mu, \frac{h_{T}}{h_{E}}=\varphi$, thus $\lambda^{2} \in\left[0, \frac{1}{h_{M}^{2}}\right]$, $\mu^{2} \in\left[0, \frac{1}{h_{M}^{2}}\right], \varphi^{2} \in\left[0, \frac{1}{h_{E}^{2}}\right]$ because $\theta>c_{n}, \theta \eta>\gamma^{2}$, and $c_{n}-h_{j}^{2}(\Delta-a)^{2}>0(j=$ $M, E, T)$. (1) Based on Proposition 2 and Proposition 3, we can derive that $\tau^{\mathrm{M}^{*}}-\tau^{\mathrm{E}^{*}}=$ $\frac{\eta h_{M}(\Delta-a)\left(\theta-c_{n}\right) X_{4}(\lambda)}{\left(4 \theta \eta-\gamma^{2}-2 G_{M}\right)\left(4 \theta \eta-\gamma^{2}-G_{E}\right)}$, where $X_{4}(\lambda)=4 \theta \eta-\gamma^{2}-\left(4 \theta \eta-\gamma^{2}-G_{M}\right) \lambda^{2}$. From the properties of quadratic function, it is easy to conclude that a unique optimal solution 
exists: $\lambda_{4}^{*}=\sqrt{1+\frac{G_{M}}{4 \theta \eta-\gamma^{2}-G_{M}}}$. Additionally, because $-\left(4 \theta \eta-\gamma^{2}-G_{M}\right)<0$, when $\lambda>\lambda_{4}^{*}$, we have $\tau^{\mathrm{M}^{*}}<\tau^{\mathrm{E}^{*}}$ or $\tau^{\mathrm{M}^{*}}>\tau^{\mathrm{E}^{*}}$.

(2) Based on Proposition 2 and Proposition 4, we can easily assert that $\tau^{\mathrm{M}^{*}}-\tau^{\mathrm{T}^{*}}=$ $\frac{\eta h_{M}^{2}(\Delta-a)\left(\theta-c_{n}\right)\left(4 \theta \eta-\gamma^{2}\right)\left(2-\mu^{2}\right)}{2\left(4 \theta \eta-\gamma^{2}-2 G_{M}\right)\left(4 \theta \eta-\gamma^{2}-G_{T}\right)}$. It is obvious that when $\mu>\sqrt{2}$, we have $\tau^{\mathrm{M}^{*}}<\tau^{\mathrm{T}^{*}}$ or $\tau^{\mathrm{M}^{*}}>\tau^{\mathrm{T}^{*}}$.

(3) Based on Proposition 3 and Proposition 4, we can easily drive that $\tau^{\mathrm{E}^{*}}-\tau^{\mathrm{T}^{*}}=$ $\frac{\eta h_{E}^{2}(\Delta-a)\left(\theta-c_{n}\right) Z_{4}(\varphi)}{2\left(4 \theta \eta-\gamma^{2}-G_{E}\right)\left(4 \theta \eta-\gamma^{2}-G_{T}\right)}$, where $Z_{4}(\varphi)=2\left(4 \theta \eta-\gamma^{2}\right)-\left(4 \theta \eta-\gamma^{2}+G_{E}\right) \varphi^{2}$ From the properties of quadratic function, it is easy to conclude that a unique optimal solution exists $\varphi_{4}^{*}=\sqrt{2-\frac{G_{E}}{4 \theta \eta-\gamma^{2}+G_{E}}}$. Additionally, because $-\left(4 \theta \eta-\gamma^{2}+G_{E}\right)<0$, when $\varphi>\varphi_{4}^{*}$, we have $\tau^{\mathrm{E}^{*}}<\tau^{\mathrm{T}^{*}}$ or $\pi_{M}^{\mathrm{T}^{*}}<\pi_{M}^{\mathrm{E}^{*}} \cdot \square$

\section{References}

1. Feng, L.; Govindan, K.; Li, C. Strategic planning: Design and coordination for dual-recycling channel reverse supply chain considering consumer behavior. Eur. J. Oper. Res. 2017, 260, 601-612. [CrossRef]

2. Li, C.; Feng, L.P.; Luo, S.Y. Strategic introduction of an Online recycling channel in the reverse supply chain with a random demand. J. Clean. Prod. 2019, 236, 117683. [CrossRef]

3. Islam, M.T.; Abdullah, A.B.; Shahir, S.A.; Kalam, M.A.; Masjuki, H.H.; Shumon, R.; Rashid, M.H. A public survey on knowledge, awareness, attitude and willingness to pay for WEEE management: Case study in Bangladesh. J. Clean. Prod. 2016, 137, 728-740. [CrossRef]

4. Wang, W.; Ding, J.; Sun, H. Reward-penalty mechanism for a two-period closed-loop supply chain. J. Clean. Prod. 2018, 203, 898-917. [CrossRef]

5. Zhang, Z.; Wang, Z.; Liu, L. Retail Services and Pricing Decisions in a Closed-Loop Supply Chain with Remanufacturing. Sustainability 2015, 7, 2373-2396. [CrossRef]

6. Yu, L.; He, W.; Li, G.; Huang, J.; Zhu, H. The development of WEEE management and effects of the fund policy for subsidizing WEEE treating in China. Waste Manag. 2014, 34, 1705-1714. [CrossRef]

7. Franke, C.; Basdere, B.; Ciupek, M.; Seliger, S. Remanufacturing of mobile phones-capacity, program and facility adaptation planning. Omega 2006, 34, 562-570. [CrossRef]

8. Shekarian, E.; Flapper, S.D. Analyzing the Structure of Closed-Loop Supply Chains: A Game Theory Perspective. Sustainability 2021, 13, 1397. [CrossRef]

9. Tanskanen, P. Management and recycling of electronic waste. Acta Mater. 2013, 61, 1001-1011. [CrossRef]

10. Qu, Y.; Zhu, Q.; Sarkis, J.; Geng, Y.; Zhong, Y. A review of developing an e-wastes collection system in Dalian, China. J. Clean. Prod. 2013, 52, 176-184. [CrossRef]

11. Eberhardt, L.C.; Stijn, A.V.; Rasmussen, F.N.; Birkved, M.; Birgisdottir, H. Development of a Life Cycle Assessment Allocation Approach for Circular Economy in the Built Environment. Sustainability 2020, 12, 9579. [CrossRef]

12. Atasu, A.; Sarvary, M.; Wassenhove, L.N. Remanufacturing as a marketing strategy. Manag. Sci. 2008, 54, 1731-1746. [CrossRef]

13. Ferrer, G.; Swaminathan, J.M. Managing new and differentiated remanufactured products. Eur. J. Oper. Res. 2010, 203, 370-379. [CrossRef]

14. Subramanian, R.; Subramanyam, R. Key factors in the market for remanufactured products. Manuf. Serv. Oper. Manag. 2012, 14, 315-326. [CrossRef]

15. Huang, Y.; Wang, Z. Demand disruptions, pricing and production decisions in a closed-loop supply chain with technology licensing. J. Clean. Prod. 2018, 191, 248-260. [CrossRef]

16. Gong, Y.; Chen, M.; Wang, Z.; Zhan, J. With or without deposit-refund system for a network platform-led electronic closed-loop supply chain. J. Clean. Prod. 2021, 281, 125356. [CrossRef]

17. Huang, M.; Song, M.; Lee, L.H.; Ching, W.K. Analysis for strategy of closed-loop supply chain with dual recycling channel. Int. J. Prod. Econ. 2013, 144, 510-520. [CrossRef]

18. Zhao, S.; Zhu, Q. Remanufacturing supply chain coordination under the stochastic remanufacturability rate and the random demand. Ann. Oper. Res. 2017, 257, 661-695. [CrossRef]

19. Hong, X.; Wang, Z.; Wang, D.; Zhang, H. Decision models of closed-loop supply chain with remanufacturing under hybrid dual-channel collection. Int. J. Adv. Manuf. Tech. 2013, 68, 1851-1865. [CrossRef]

20. Ferrer, G.; Swaminathan, J.M. Managing New and Remanufactured Products. Manag. Sci. 2006, 52, 15-26. [CrossRef] 
21. Chen, J.M.; Chang, C.I. Dynamic pricing for new and remanufactured products in a closed-loop supply chain. Int. J. Prod. Econ. 2013, 146, 153-160. [CrossRef]

22. Xiong, Y.; Zhou, Y.; Li, G.; Chan, H.; Xiong, Z. Don't forget your supplier when remanufacturing. Eur. J. Oper. Res. 2013, 230, 15-25. [CrossRef]

23. $\mathrm{Wu}, \mathrm{C} . \mathrm{H}$. Price and service competition between new and remanufactured products in a two-echelon supply chain. Int. J. Prod. Econ. 2012, 140, 496-507. [CrossRef]

24. Li, G.; Li, L.; Sun, J. Pricing and service effort strategy in a dual-channel supply chain with showrooming effect. Transport. Res. E-Log. 2019, 126, 32-48. [CrossRef]

25. Duan, C.; Xiu, G.; Yao, F. Multi-Period E-Closed-Loop Supply Chain Network Considering Consumers' Preference for Products and AI-Push. Sustainability 2019, 11, 4571. [CrossRef]

26. He, Q.; Wang, N.; Yang, Z.; He, Z.; Jiang, B. Competitive collection under channel inconvenience in closed-loop supply chain. Eur. J. Oper. Res. 2019, 275, 155-166. [CrossRef]

27. Tsay, A.A.; Agrawal, N. Channel Dynamics under Price and Service Competition. Manuf. Serv. Oper. Manag. 2000, 2, 372-391. [CrossRef]

28. Choi, T.M.; Li, Y.; Xu, L. Channel leadership, performance and coordination in closed loop supply chains. Int. J. Prod. Econ. 2013, 146, 371-380. [CrossRef]

29. Dey, S.K.; Giri, B.C. Analyzing a closed-loop sustainable supply chain with duopolistic retailers under different game structures. CIRP J. Manuf. Sci. Technol. 2021, 33, 222-233. [CrossRef]

30. Savaskan, R.C.; Bhattacharya, S.; Wassenhove, L.N.V. Closed-Loop Supply Chain Models with Product Remanufacturing. Manag. Sci. 2004, 50, 239-252. [CrossRef]

31. Savaskan, R.C.; Van Wassenhove, L.N. Reverse Channel Design: The Case of Competing Retailers. Manag. Sci. 2006, 52, 1-14. [CrossRef]

32. Yi, P.; Huang, M.; Guo, L.; Shi, T. Dual recycling channel decision in retailer oriented closed-loop supply chain for construction machinery remanufacturing. J. Clean. Prod. 2016, 137, 1393-1405. [CrossRef]

33. Atasu, A.; Toktay, L.B.; Wassenhove, L. How Collection Cost Structure Drives a Manufacturer's Reverse Channel Choice. Prod. Oper. Manag. 2013, 22, 1089-1102. [CrossRef]

34. Chuang, C.H.; Wang, C.X.; Zhao, Y. Closed-loop supply chain models for a high-tech product under alternative reverse channel and collection cost structures. Int. J. Prod. Econ. 2014, 156, 108-123. [CrossRef]

35. Ma, P.; Li, K.W.; Wang, Z.J. Pricing decisions in closed-loop supply chains with marketing effort and fairness concerns. Int. J. Prod. Res. 2017, 55, 6710-6731. [CrossRef]

36. Giovanni, P.D.; Zaccour, G. A two-period game of a closed-loop supply chain. Eur. J. Oper. Res. 2014, 232, 22-40. [CrossRef]

37. Guide, V.D.R.; Jayaraman, V.; Linton, J.D. Building contingency planning for closed-loop supply chains with product recovery. J. Oper. Manag. 2003, 21, 259-279. [CrossRef]

38. Guide, V.D.R.; Wassenhove, L.N.V. Managing product returns for remanufacturing. Prod. Oper. Manag. 2001, 10, 142-155. [CrossRef] 